\title{
A review of GPS/GLONASS studies of the ionospheric response to natural and anthropogenic processes and phenomena
}

\author{
Edward L. Afraimovich ${ }^{1}$, Elvira I. Astafyeva ${ }^{1,2}$, Vladislav V. Demyanov ${ }^{3}$, Ilya K. Edemskiy ${ }^{1}$, \\ Nadezhda S. Gavrilyuk ${ }^{1}$, Artem B. Ishin ${ }^{1}$, Eugene A. Kosogorov ${ }^{1}$, Lyudmila A. Leonovich ${ }^{1}$, Oleg S. Lesyuta ${ }^{1}$, \\ Kirill S. Palamartchouk ${ }^{4}$, Natalia P. Perevalova ${ }^{1}$, Anna S. Polyakova ${ }^{1}$, Gennadyi Y. Smolkov ${ }^{1}$, \\ Sergey V. Voeykov ${ }^{1}$, Yury V. Yasyukevich ${ }^{1, *}$, and Ilya V. Zhivetiev ${ }^{5}$ \\ 1 The Institute of Solar-Terrestrial Physics (ISTP SB RAS), Irkutsk, PO Box 291, Russia \\ *Corresponding author: yasukevich@iszf.irk.ru \\ 2 Institut de Physique du Globe de Paris, 35 rue Hélène Brion, 75013 Paris, France \\ 3 Irkutsk State Railway University, 664074 Irkutsk, Russia \\ 4 School of Civil Engineering and Geosciences, Newcastle University, UK \\ 5 Institute of Cosmophysical Research and Radiowave Propagation FEB RAS, Paratunka, Russia
}

Received 4 April 2012 / Accepted 19 July 2013

\begin{abstract}
The article is a review of studies of ionospheric effects carried out in ISTP SB RAS. The main results of GPS/GLONASS radio sounding of ionospheric disturbances of natural and anthropogenic origin are presented. The article is devoted to ionospheric effects of solar eclipses, solar flares, solar terminator, earthquakes, tropical cyclones, large-scale ionospheric disturbances of auroral origin, rocket launches. Dynamics of global electron content analysis is also presented. The special attention is paid on the influence of solar flares and ionospheric irregularities on GPS and GLONASS performance. The work is a tribute to the leader of GNSS-monitoring workgroup Prof. E.L. Afraimovich (12 March 1940-8 November 2009).
\end{abstract}

Key words. ionosphere - global TEC - remote sensing

\section{Introduction}

The Earth's ionosphere is closely related to other geospheres. In this regard, the ionosphere can be considered as a natural indicator of disturbances in near-Earth space. Natural and anthropogenic disturbances may cause wave disturbances of ionospheric parameters and change the ionospheric dynamics throughout the world.

Development of the GPS and GLONASS systems has contributed significantly to ionospheric studies. The GPS/ GLONASS technology allows us to determine total electron content (TEC) variations along the path from a receiver to a satellite with the use of phase measurements at two frequencies. Ionospheric wave disturbances become detectable using several spaced GPS/GLONASS receivers. There are several scientific groups dealing with GPS/GLONASS ionospheric studies.

The global network of GPS/GLONASS stations consists of more than 3000 receivers now. Data from these receivers are freely available on the Internet. Along with the global network of GPS/GLONASS receivers, there are dense regional networks - in Japan (GEONET, more than 1200 receivers), Germany, Italy, etc. Some data from these networks are available on the Internet as well.

According to the concept of "Global detector" (GLOBDET), the entire network of GPS/GLONASS receivers can be used as a network of tracking stations for examining the ionosphere (Fig. 1). The spacing of GPS/GLONASS stations is uneven. In spite of this, now one can solve the problem of the global detection of disturbances with the spatial resolution, which was previously impossible.

This paper is a review of studies of ionospheric response to natural and anthropogenic forcing on the Earth's ionosphere. The analysis is based on GPS sounding data. Presented here are the results of effects of solar eclipses, solar flares, solar terminator, earthquakes, tropical cyclones and large-scale disturbances having auroral origin. The ionospheric response to space vehicle launches is considered as anthropogenic forcing. The purpose of the current paper is to collect together and summarise the results of previous papers, and to highlight the contribution of Prof. E.L. Afraimovich to the area of ionospheric studies using GPS/GLONASS. The reader can find more details in the referenced papers.

\section{GPS/GLONASS sounding of the ionosphere}

The technique for reconstructing the oblique TEC with data from dual-frequency GPS/GLONASS receivers is fairly well developed and described in several papers (HofmannWellenhof et al. 1992; Afraimovich \& Perevalova 2006). The TEC measurement unit is TECU $\left(10^{16} \mathrm{~m}^{-2}\right)$. TEC 


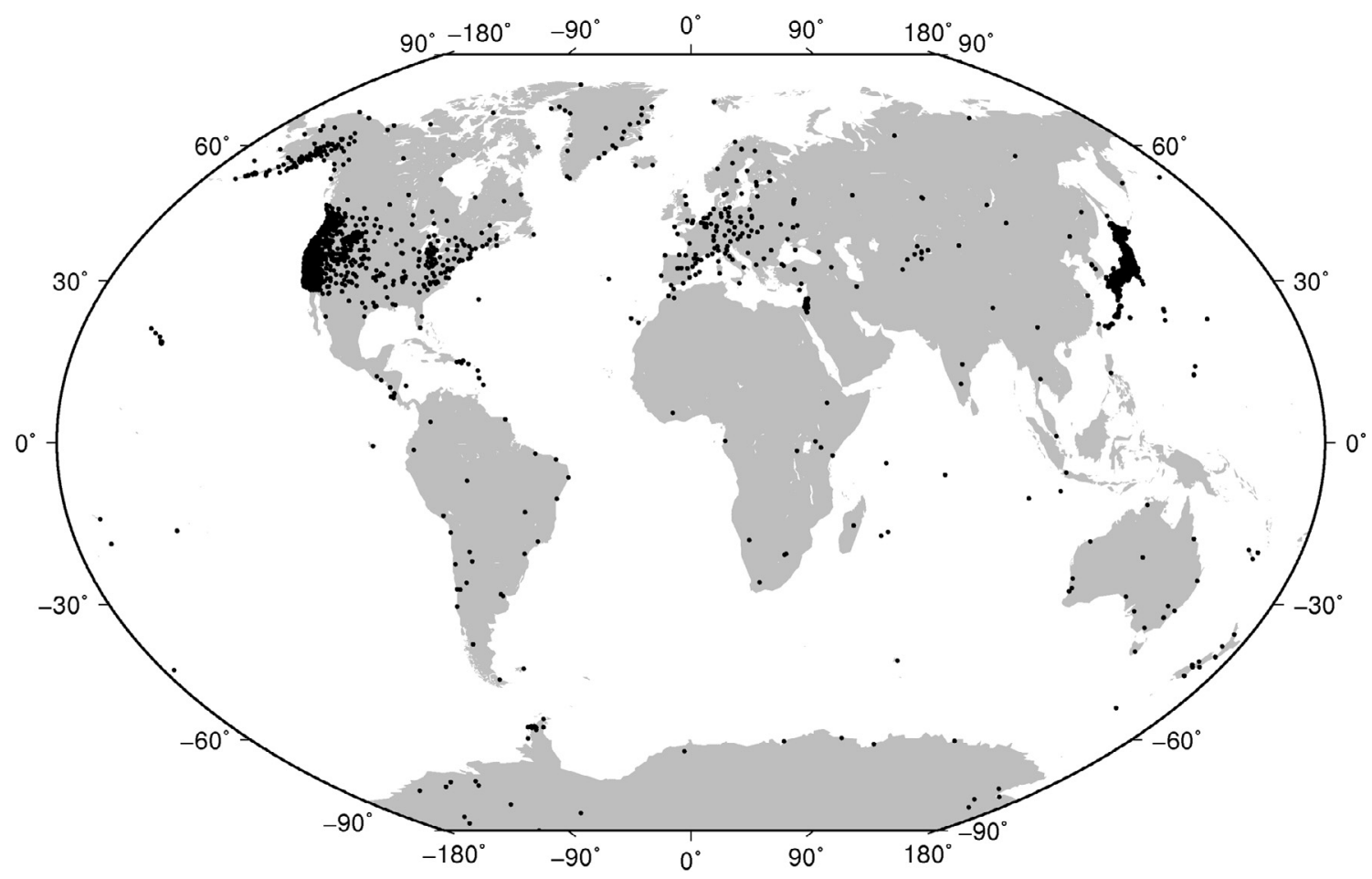

Fig. 1. Distribution of tracking stations being a part of the global GPS detector of ionospheric disturbances.

along « receivers - satellite » line-of-sight can be determined from phase measurements as follows:

$$
I=\frac{1}{40.308} \frac{f_{1}^{2} f_{2}^{2}}{f_{1}^{2}-f_{2}^{2}}\left[\left(L_{1} \lambda_{1}-L_{2} \lambda_{2}\right)+K+n L\right],
$$

where $L_{1} \lambda_{1}$ and $L_{2} \lambda_{2}$ are the phase paths of radio signal (m); $L_{1}$ and $L_{2}$ represent the number of phase rotations at frequencies $f_{1}$ and $f_{2} ; \lambda_{1}$ and $\lambda_{2}$ stand for the corresponding wavelengths (m); $K$ is the unknown initial phase path caused by an unknown number of total phase rotations along the lineof-sight (LOS) (m); and $n L$ are the errors in determining the phase path $(\mathrm{m})$.

The error in determining the absolute TEC from the group delay may be up to $30-50 \%$ (sometimes up to $100 \%$ ) (Kunitsyn et al. 2007), whereas the error in determining TEC variations from phase measurements with formula (1) is less than $0.1 \%$ relative to the background concentration; the absolute TEC value is however unknown in this case.

At the L2 frequency, the signal-to-noise ratio is lower than those at the L1 frequency. It is due to the fact that GPS satellite's transmitter power at L2 is $6 \mathrm{~dB}$ less than that at L1 (ICD-200c). The same is for the Russian GLONASS system. The transmitter power at L1 is 30 watt; that at L2, 21 watt (Perov \& Kharisov 2005). Moreover, majority of receivers have no access to the military "Y" code, and they are to use the codeless or semi-codeless receiving mode. In this case, signal-to-noise ratio is decreased. As a result, the signal-to-noise ratio at $\mathrm{L} 2$ is, at best, $13 \mathrm{~dB}$ lower than the mode of fully coded receiving. The difference between L1 and L2 signal powers for semi-codeless receivers may be much more than $10 \mathrm{~dB}$. So less strong scintillations (as compared with those for L1) can lead to L2 loss-of-lock. Consequently, information on the L2 signal lock loss may be considered as indirect evidence of GPS signal scintillations, and it may be used as an indirect parameter to reflect the scintillation level for all kinds of GPS receivers on a global scale (Afraimovich et al. 2002c, 2009d).

To study general dynamics of the ionosphere, TEC global maps can be used; their computation algorithm is presented in (Mannucci et al. 1998; Schaer et al. 1998). The technique for producing Global Ionospheric Maps (GIM) was developed by several laboratories (JPL, USA; CODE, Switzerland, etc.). Global Ionospheric Maps are generated using data from the worldwide network of GPS receivers in different research centres:

1. Geodetic Survey Division of Natural Resources, Canada (EMRG) (http://www.nrcan-rncan.gc.ca/),

2. Center for Orbit Determination in Europe, University of Berne, Switzerland (CODE) (http://www.cx.unibe.ch/),

3. Jet Propulsion Laboratory of California Institute of Technology (JPLG) (http://www.jpl.nasa.gov/),

4. Research group of Astronomy and GEomatics of the Technical University of Catalonia (gAGE/UPC) (http:// www.upc.es/),

5. European Space Agency (ESA) (http://www.esa.int), etc.

Being developed in the above centres, the algorithms for reconstructing the TEC space-time distribution are described in detail in (Mannucci et al. 1998; Schaer et al. 1998; Hernandez-Pajares et al. 1999). In spite of difference between these algorithms, the general concept of the absolute vertical TEC reconstruction is based on selection of optimal parameters for the selected model. For the chosen model the expected ionospheric correction is calculated for real GPS lines-of-sight. The estimated correction values are then compared with the measured one for different parameters of the $\mathrm{N}(\mathrm{h})$ profile 
model. This process is repeated until disparities are minimal. After that, the vertical TEC for GIM cell is calculated for evaluated model parameters. In some cases, model of the thin ionospheric layer at the given height is used; sometimes, a dual-layer voxel model is employed. For the chosen model, values of the expected ionospheric correction for the value of distance to the GPS satellite are calculated for real values of GPS angle of view. The estimated correction values are then compared with the measured ones. For different parameters of the $\mathrm{N}(\mathrm{h})$ profile model, this process is repeated until disparities are minimum. Next, the vertical TEC equal to the mean TEC for the corresponding GIM cell is calculated for the optimal $\mathrm{N}(\mathrm{h})$ profile (with minimum root mean square).

The spatial range of GIMs in IONEX format (ftp://cddisa.gsfc.nasa.gov/pub/gps/products/ionex/) is from $0^{\circ}$ to $360^{\circ}$ in longitude and from $-87.5^{\circ}$ to $87.5^{\circ}$ in latitude; dimensions of the elementary GIM cell are $5^{\circ}$ in longitude and $2.5^{\circ}$ in latitude. For each moment of time with temporal resolution of $2 \mathrm{~h}$, values of the vertical TEC $\mathrm{I}_{\mathrm{i}, \mathrm{j}}$ are known from IONEX files; here, indices $i, j$ denote coordinates (latitude and longitude) of the GIM cell.

\section{Ionospheric effects of solar eclipses}

Observations of ionospheric disturbances during solar eclipses make it possible to obtain information on processes in the Moon's shadow and its vicinities. Besides, variations in solar flux can be estimated quite precisely. In the general case, the ionospheric response to the Moon's umbral shadow passing through the upper atmosphere manifests itself in:

- the TEC decrease;

- increase in the minimum height of the F layer;

- increase in actual reflection height of radio waves of different frequencies;

- drop in concentration in the F-layer maximum.

These effects are typical of transition to the night-time ionosphere.

In 1998, Afraimovich et al. (1998) performed the first study of ionospheric effects of solar eclipses, based on GPS data. This paper was followed by a large amount of data obtained in Tsai \& Liu (1999). The main parameters of the ionospheric response to eclipses are the delay value $\tau$ relative to the maximum phase of eclipse, its amplitude $A$ and duration $\Delta T$. Almost all the papers dealing with the ionospheric response to solar eclipses provide estimation of these parameters. Table 1 lists measurements of these parameters with GPS. Column "Technique" shows data on the temporal resolution of method and the number $n$ of stations being used.

Values $\tau, A, \Delta T$ obtained from studying the ionospheric response to total solar eclipses with GPS differ significantly. Value $\tau$ varies from 0 to $140 \mathrm{~min}$; A, from 0.15 to 15 TECU; $\Delta T$, from 50 to $240 \mathrm{~min}$. Such a difference may be caused by the difference in longitudinal and latitudinal ranges over which the study was carried out, as well as by season, technique for GPS data processing and geomagnetic conditions. The paper by Tsai \& Liu (1999), for instance, deals with the study conducted near the magnetic equator. Thus, TEC series include not only the response to solar eclipses but also variations caused by dynamics of the equatorial anomaly. Le et al. (2009a, 2009b) studied ionospheric behavior in conjugate hemispheres during

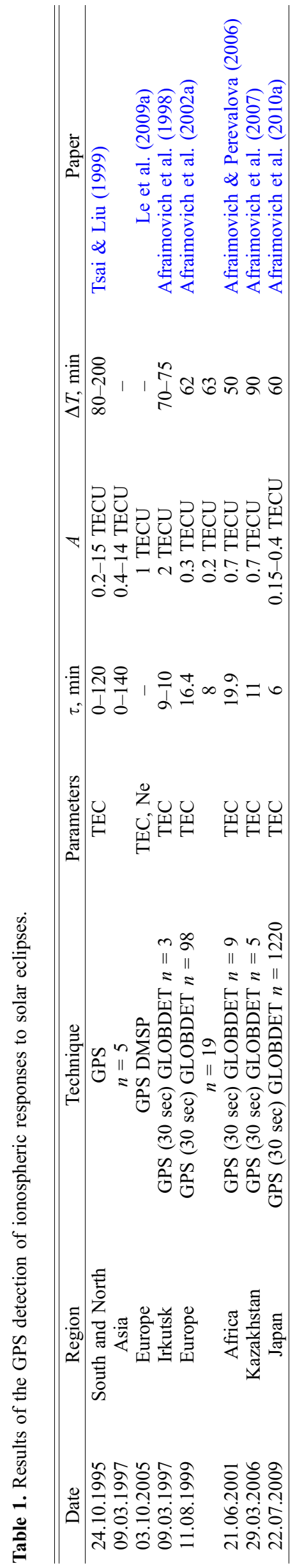




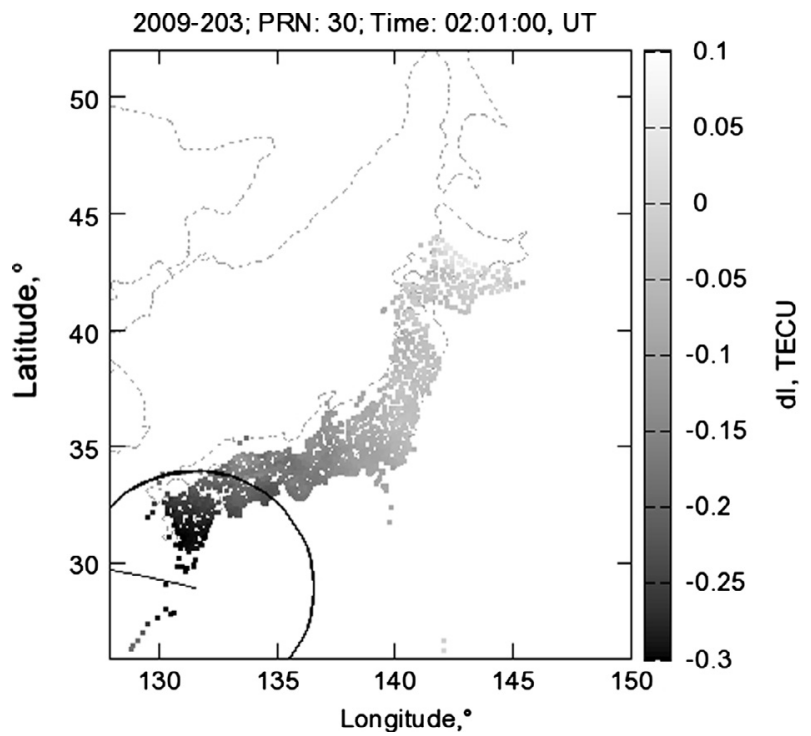

Fig. 2. Instant spatial distribution of the amplitude of 60-min TEC variations above Japan during the solar eclipse of 22 July 2009 (02:01 UT) (figure taken from Afraimovich et al. 2010a).

2005 solar eclipse and latitudinal dependence of the ionospheric response to solar eclipses.

At the same time, Global Ionospheric Maps (GIM) do not provide the necessary determination accuracy of $\tau, A$ and $\Delta T$. This is due to low temporal resolution of standard GIM (2 h). Parameter $\Delta T$ is $1-1.5 \mathrm{~h}$ which is evident from data taken from different papers.

Regional networks of GPS receivers have provided a new possibility of analyzing solar eclipses. The solar eclipse of 22 July 2009 took place near GEONET, the densest network of GPS receivers (1220 stations). This fact made it possible to establish a nearly linear decrease in amplitude of the ionospheric response from -0.4 down to -0.15 TECU with distance away from trajectory of the total eclipse. This is obvious from the spatial distribution of amplitude of 60-min TEC variations (boundary of $90 \%$ obscuration of the Sun is shown by the black circle in Fig. 2).

\section{Ionospheric effects of solar terminator}

Early researches have revealed that the motion of solar terminator (ST) generates acoustic-gravity waves (AGWs), instabilities and fluctuations in ionospheric plasma (Cot \& Teitelbaum 1980; Somsikov 1983). Among all AGW sources, moving ST has a special place. Its spatial and temporal characteristics are well known. However, all experimental studies have mainly been conducted at certain stations, using indirect methods of spectral analysis. Besides, they have been made only for temporal variations of ionospheric parameters that can be affected by various factors.

In 2008, (Afraimovich 2008; Afraimovich et al. 2009a) first confirmed the existence of the wave structure generated by STs moving above the USA, Europe and Japan with the use of GPS TEC data. They analysed several days in autumn and winter. The TEC disturbances can be divided into two groups (Fig. 3a):
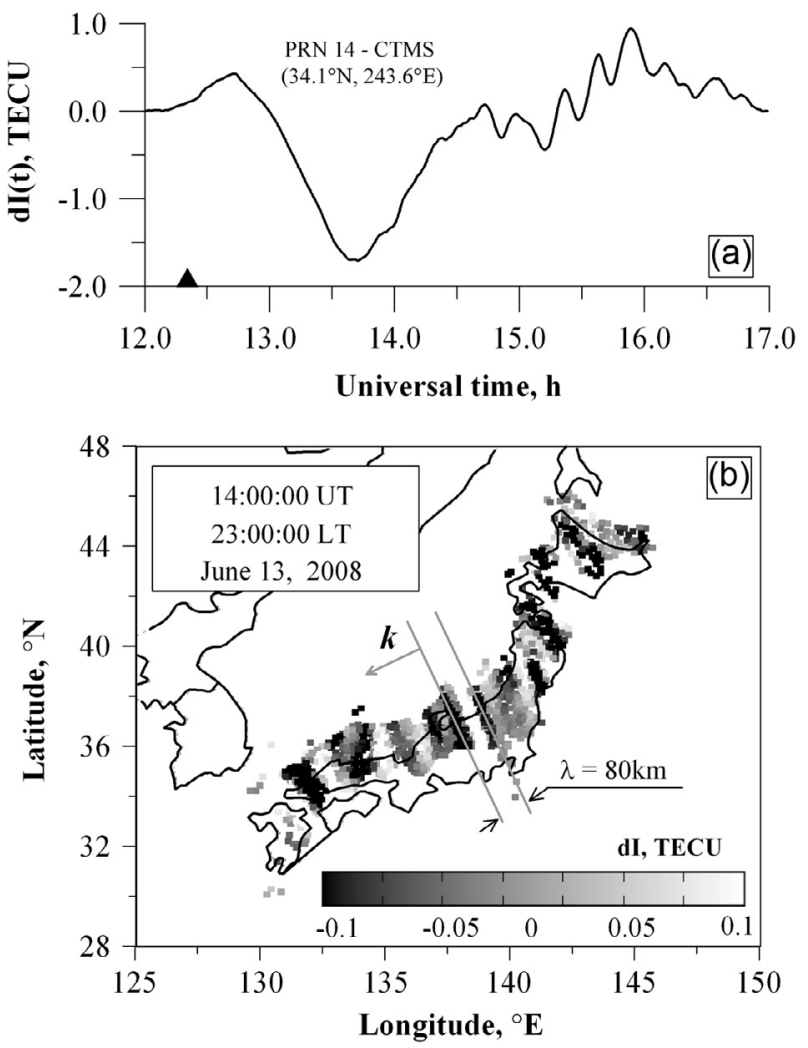

Fig. 3. (a) Large-scale and medium-scale TEC variations observed after the ST passage. (b) Spatial structure of the "terminator" wave disturbance of TECs above Japan (figure taken from Afraimovich et al. 2009a).

- Large-scale (LS) disturbances. These are 60-min variations having amplitude of about 1 TECU.

- Medium-scale (MS) disturbances. These are 15-min variations having amplitude of about 0.2 TECU.

The first group of disturbances was predicted in theoretical studies. Besides, it was recorded before with different ionospheric-sounding techniques. The second group of disturbances is referred to as travelling wave packets (TWPs). It was first identified as a new manifestation of "terminator" waves.

The TWP generation is observed when values of the TEC time derivative are maximum. Their duration is $1-2 \mathrm{~h}$. The recording starts 2-3 $\mathrm{h}$ after the ST appearance at $100 \mathrm{~km}$. LS and MS disturbances of TEC are observed along the ST front over a distance of no less than $1600 \mathrm{~km}$. The TWP relative amplitude $(\sim 0.2 \%)$ and time period $(\sim 15 \mathrm{~min})$ are quite small. This is the most probable reason why this phenomenon has never been recorded before.

More detailed studies of TWP reveal that TWP fluctuations last about $10-30 \mathrm{~min}$, the total duration can be up to $6 \mathrm{~h}$ and the wavelength is from 100 to $300 \mathrm{~km}$ (Afraimovich et al. 2009a; Afraimovich et al. 2010b). The TWP spatial structure is characterised by a high degree of anisotropy and coherence at more than 10 wavelengths (Fig. 3b). AGW and their related TIDs are known to propagate at no more than 3-5 wavelengths, with no significant attenuation, variation in its form or loss of coherence (Drobzhev et al. 1991). At the same time, MS TWPs can propagate as far as $\sim 1000 \mathrm{~km}$ (Afraimovich et al. 2003).

A large amount of statistical material was used to analyse TWP spectral characteristics. Spectral characteristics of TEC 
E.L. Afraimovich et al.: A review of GPS/GLONASS studies of the ionospheric response

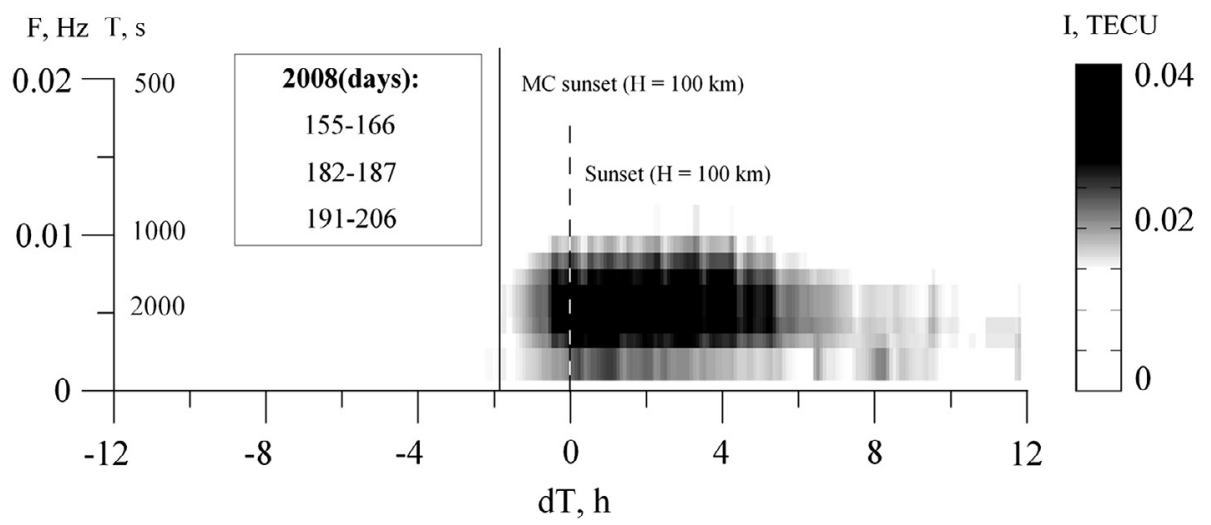

Fig. 4. Dynamic spectrum of filtered (2-30 min) TEC variations above Japan during 35 summer days in 2008 . TWPs are recorded $1.5 \mathrm{~h}$ before and during sunset at the magneto-conjugate point (figure taken from Afraimovich et al. 2009c).

variations were analysed using data for different seasons of 2008. Each dynamical spectrum was calculated using $\sim 3 \times 10^{7}$ rows of continuous raw data (Afraimovich et al. 2009b). The time of the TWP appearance was found out to depend greatly on season. In winter, TWPs in the Northern hemisphere are observed mainly $3 \mathrm{~h}$ after the passage of the morning solar terminator, when the TEC derivative is maximum (Afraimovich et al. 2009b). At equinoxes, TWPs appear after the ST passage without any significant delay or lead. In summer, TWPs are recorded $1.5-2 \mathrm{~h}$ prior to the ST appearance at an observation site (Fig. 4). It was found later that seasonal variations of TWP recording time correspond well with the moment of the ST passage over the magneto-conjugate area (Voeykov et al. 2011).

Recording of TWPs $1.5 \mathrm{~h}$ prior to the ST passage over an observation site is the strongest argument for no AGW model of wave packets. This is true, at least, for the night-time summer observations. For each season, connection between the TWP appearance and the ST appearance at the magneto-conjugate point is observed. This implies that the TWP generation depends on a number of phenomena at magneto-conjugate points and in the magnetic field line that connects these points (Afraimovich et al. 2009c). These findings are in qualitative agreement with simulation results (Huba \& Joyce 2000). Model SAMI2 showed that rapid heating (cooling), which occurs at sunrise (sunset), excites ion-sound waves with periods of about tens of minutes (Huba \& Joyce 2000). These waves can exist during the period of about $1-3 \mathrm{~h}$ at altitudes $\sim 1000 \mathrm{~km}$.

\section{Ionospheric effects of solar flares}

Solar radiation affects the Earth's upper atmosphere. The sharpest variations in ionising radiation in near-Earth space are observed during solar flares (SFs). SF is a sudden and rapid release of energy in the upper chromosphere and lower corona of the Sun. Energy of about $10^{23}-10^{25} \mathrm{~J}$ is released during powerful SFs, which is much less than the total energy flux from the Sun (more than $10^{40} \mathrm{~J}$ ). However, SF qualitatively changes the spectral composition of solar radiation. In the X-ray range of the spectrum, energy flux increases significantly (up to $10^{5}$ times). In the UV range, it increases by tens of percent. This magnitude is smaller but, nevertheless, it is rather significant (Mitra 1974).

The paper (Afraimovich 2000) puts forward a new technique for global GPS detection of response to SFs. This tech- nique is now widely used all over the world, together with other solar observation satellites (Liu 2004). To determine the ionospheric response to SFs, the method of coherent summation of TEC time derivatives was employed. These values were determined simultaneously for all the GPS satellites, at all GPS stations under analysis. Measurements of parameters of the ionospheric response to SFs were presented in (Donnelly 1971; Mendillo et al. 1974; Mitra 1974; Liu 1996; Thomson et al. 2005; Afraimovich et al. 2001b; Qian 2011). The height region of response, which is mainly responsible for TEC variations, has been first determined in (Leonovich et al. 2002). The analysis relied on the use of the effect of the atmosphere's partial obscuration by the Earth (Fig. 5). LOSs near the ST boundary were chosen for the technique suggested in (Afraimovich 2000). These paths pass through the atmosphere in the umbra region and through the lighted atmosphere. Intersection of LOS and ST boundary is at altitude $\mathrm{h}_{0}$. The response amplitude measured in the beam may be thought of as being equal to the response in the lighted area.

The technique suggested was used to study the ionospheric TEC response to several $X$ flares. Two types of the TEC absolute increment $\Delta I$ were detected, depending on the shadow height $\mathrm{h}_{0}$ for the events under consideration (Figs. 5b and 5c) (Leonovich \& Taschilin 2008). The upper scale shows the shadow height $h_{0}$ dependence on the relative TEC response $\Delta I / I_{0}$ (in percent), where $I_{0}$ is the TEC response amplitude registered at completely sunlit LOS $\left(h_{0}=0\right)$. Figure $5 \mathrm{c}$ shows the firsttype event. Here, the TEC response takes place in the topside ionosphere $\left(h_{0}>300\right)$. During the second-type events (Fig. 5c), there is no TEC response above $300 \mathrm{~km}$.

An analysis was conducted to obtain characteristics of the flares under consideration (X-ray and optical, localisation on the Sun) in their relation to appearance of the TEC response above $300 \mathrm{~km}$. No peculiarities were revealed. In some cases (Fig. 5b), the contribution of the topside ionosphere to TEC reached $30 \%$. In other cases, the response was observed only below an altitude of $300 \mathrm{~km}$ (Fig. 5c) regardless of the flare class and localisation on the Sun. We assume that this phenomenon can be caused by different spectra of the flares under consideration.

Figure 6 presents the ionospheric response in separate satellite-receiver paths $(\mathrm{a}, \mathrm{d})$, integral response of the ionosphere $(\mathrm{b}, \mathrm{e})$ and X-radiation flux measured by BATSE spectrometer (c) and GOES-10 satellite (f) for a powerful flare M4.6 of 14 July $1998(\mathrm{a}-\mathrm{c})$ and a faint flare C2.5 of 29 July 1999 (d-f). The integral response manifests itself quite well even during 

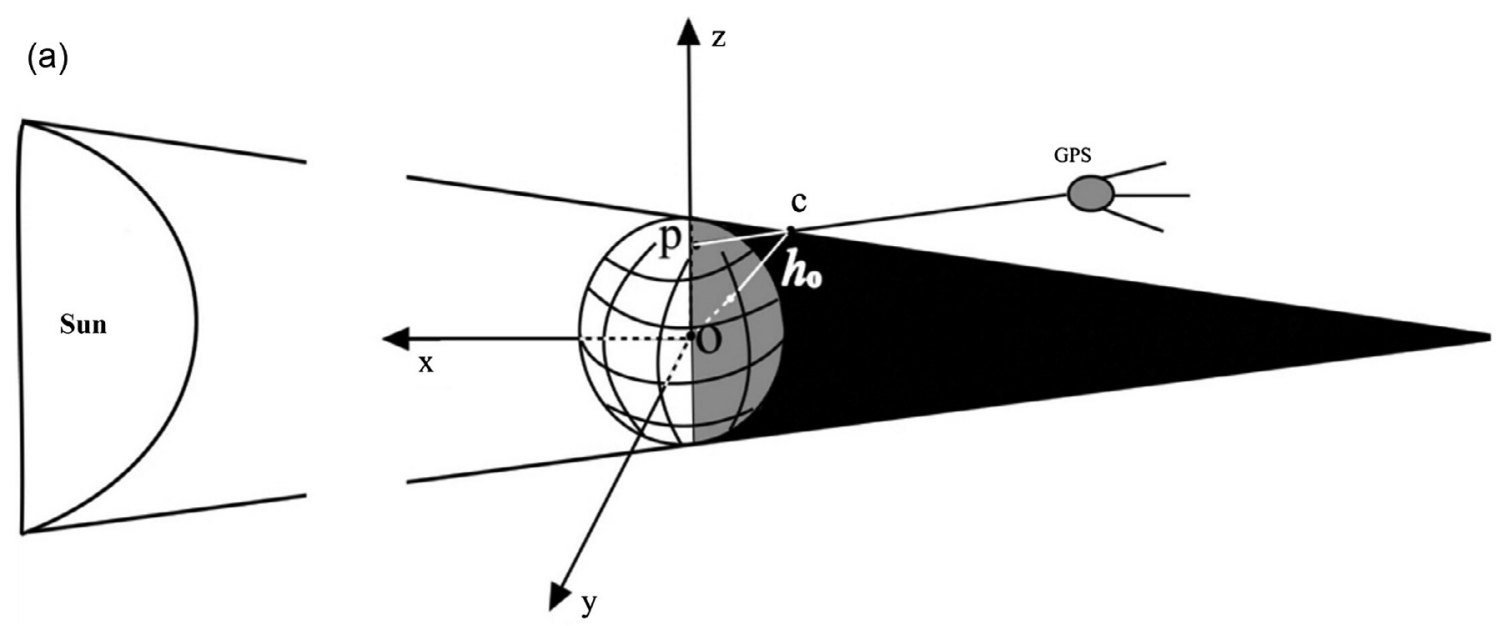

(b)

$$
\begin{aligned}
& 23 \text { July } 2002 \\
& \Delta I / I_{0} \times 100 \%
\end{aligned}
$$

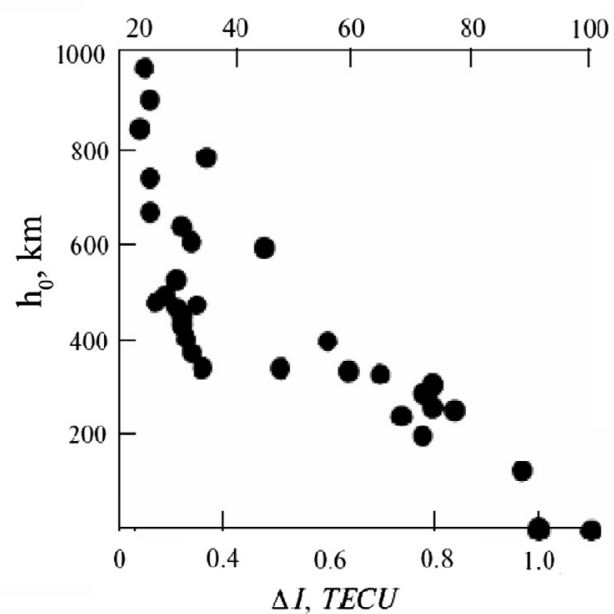

(c)

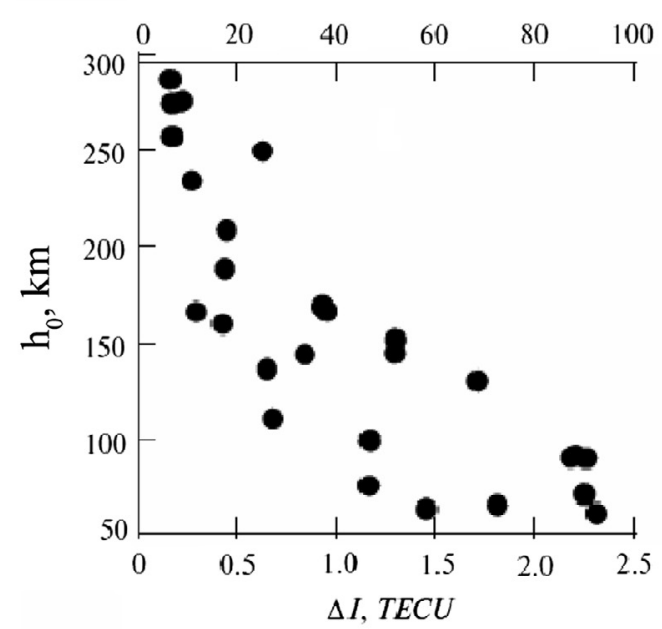

Fig. 5. (a) Pattern of the shadow of the Earth on its atmosphere (figure taken from Afraimovich \& Perevalova 2006). (b, c) Two types of the TEC absolute increment $\Delta I$ depending on the shadow height $h_{0}$ (Leonovich \& Taschilin 2008).

the faint flare (Fig. 6e); it is, however, invisible along some paths (Fig. 6d).

Observations of the ionospheric response to the powerful SFs of 23 September 1998 and 29 July 1999 were used to estimate an effective relaxation time of electrons in the ionosphere at increasing TEC values. Value $\tau$ of relaxation time was 60-100 s.

Using the GPS technology, (Afraimovich et al. 2002b; Zhang et al. 2002; Leonovich et al. 2010) analysed the dependence of the TEC response amplitude to SFs upon location of flares on the solar disc (their distance from the central solar meridian) for different flares $(\mathrm{C}, \mathrm{M}, \mathrm{X})$. Empirical dependence of the TEC response amplitude in the ionosphere $M(F)$ upon the maximum power of SFs in the soft X-ray band (1-8 A) $F$ has the form (Afraimovich et al. 2002b):

$$
M=649.4 \cdot F^{0.7} \text {. }
$$

Studies of the height contribution to the TEC response to SFs have revealed special conditions that may arise during a SF. Under these conditions, electron concentration increases and decreases in the lower and outer ionosphere, respectively
(Leonovich \& Taschilin 2008). According to simulation results (Leonovich \& Taschilin 2009), decrease in electron concentration in the outer ionosphere is caused by outflow of $\mathrm{O}+$ ions towards the plasmasphere. After the "switching-off" of a flare, plasma pressure in the F2 region decreases rapidly. Difference in pressure between the upper and lower ionosphere cannot maintain $\mathrm{O}+$ ion flow in the upward direction anymore. As a result, the ionosphere returns to its undisturbed state.

\section{Influence of solar flares and ionospheric irregularities to the GPS/GLONASS performance}

Operational reliability of the GPS system is greatly influenced by the state of near-Earth space. On the one hand, this influence should be taken into account when addressing scientific and technical questions related to operational reliability of the GPS system. On the other hand, presence of failures can characterise the state of the near-Earth space.

Several papers have shown that ionospheric irregularities can result in significant amplitude and phase distortions of GPS signals (Aarons 1999; Kintner et al. 2001; Concer 2003; Beach \& 
E.L. Afraimovich et al.: A review of GPS/GLONASS studies of the ionospheric response

Strong solar flare
14.07.1998

I(t), TECU

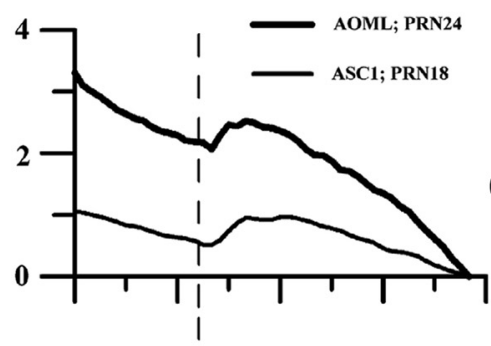

$\Sigma(\mathbf{d I} / \mathbf{d t}), \mathbf{T E C U} \cdot 10^{3} \mathbf{c}^{-1}$

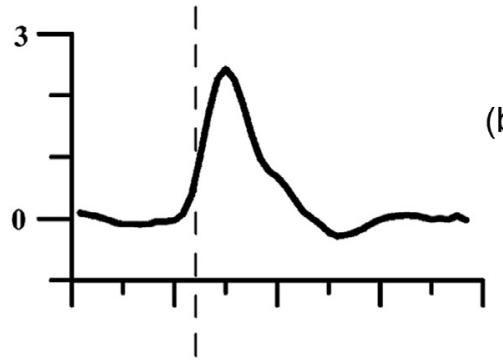

F(t), rel. units

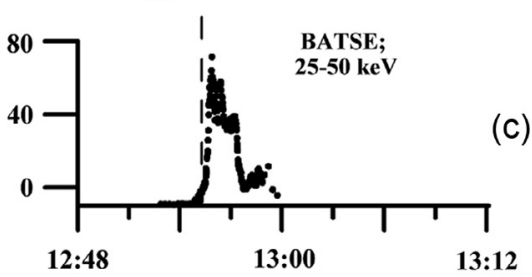

Time, UT (a)

(b)

(c)

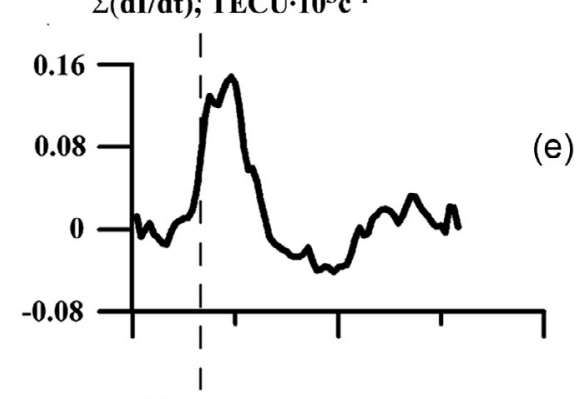

$\mathbf{F}(\mathbf{t})$, rel. units

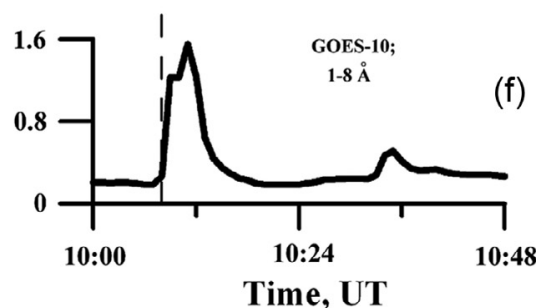

Fig. 6. TEC response to the powerful (14 July 1998) and faint (29 July 1999) solar flares (figure taken from Afraimovich \& Perevalova 2006).

Groves 2004; Béniguel et al. 2004; Campos de Rezende 2007; Kintner et al. 2009; Ledvina et al. 2002; Mushini et al. 2012; Shanmugam et al. 2012). Irregularities occurring during the main phase of a magnetic storm within the auroral oval lead to a dramatic increase in density of ranging and positioning errors. This is also correct for irregularities in the regions with increased gradient of electron concentration (Afraimovich et al. 2002c, 2009d; Afraimovich et al. 2004; Datta-Barua et al. 2003; Meggs et al. 2008).

During the magnetic storms on 29-30 October 2003 (Fig. 7), positioning error $\sigma(t)$ was up to $70-230 \mathrm{~m}$. Spikes of dependences $\sigma(t)$ (Fig. 7e) coincide with periods A, B, C of the most significant variations in intensity of the geomagnetic field. Positioning errors increase dramatically not only within the auroral zone but also in the Southwestern United States, at low $\left(30-35^{\circ} \mathrm{N}\right)$ latitudes. The increase in positioning error is accompanied with increase in mean regional values of root-mean-square deviations of TEC variations in the range of periods of 20-60 min. $(A(t)$, Fig. 7b) and $1-10 \mathrm{~min}$. $(B(t)$, Fig. 7c). Series $A(t)$ and $B(t)$ corresponding to LS and MS TID are similar for distant regions. However, increase in amplitude of TEC variations in the Southwestern United States starts about $1 \mathrm{~h}$ later. This implies that LS AGWs having large amplitude and propagating from the auroral oval generate intense medium-scale ionospheric irregularities. These MS irregularities provoke signal degradation and increase in positioning error (Ledvina et al. 2002; Meggs et al. 2008; Afraimovich et al. 2009d).
Subsequent research has revealed that ionospheric irregularities giving rise to strong scintillations may penetrate to middle latitudes both from the auroral oval and equator (ionospheric bubbles). The experiment of 12 February 2000 revealed many unusual GPS phase slips at the L2 frequency (Ma \& Maruyama 2006; Afraimovich et al. 2011). That day coincided with the main phase of magnetic storm (Dst $-100 \mathrm{nT}$ ). For analysis, we used data from the dense GPS array GEONET ( $\sim 1000$ receivers) deployed over the Japanese Islands.

The slips were shown to be caused by scintillations of GPS signals. These scintillations resulted from the scattering on small-scale irregularities being a part of larger-scale ones. Large-scale intense plasma irregularities were generated at the equator and oriented along magnetic field lines (Anderson \& Shtraus 2005; Ishin et al. 2009; Demyanov et al. 2011). Maximum number of phase slips corresponded to the line-of-sight (LOS) direction along and across the magnetic field line at the F-region maximum height. Figure 8 presents dependence of slip density $P(\gamma)$ on the angle between LOS and the magnetic field $\gamma$. Measurements made by two satellites show an increase in the number of slips at an angle $\gamma$ of about $90^{\circ}$; measurements made by two other satellites, at an angle $\gamma$ of about $0^{\circ}$. As for satellite PRN13, there were phase slips at the additional frequency at ionospheric heights (in more than 30 percent of cases) when the satellite-receiver path was directed along the magnetic field. 


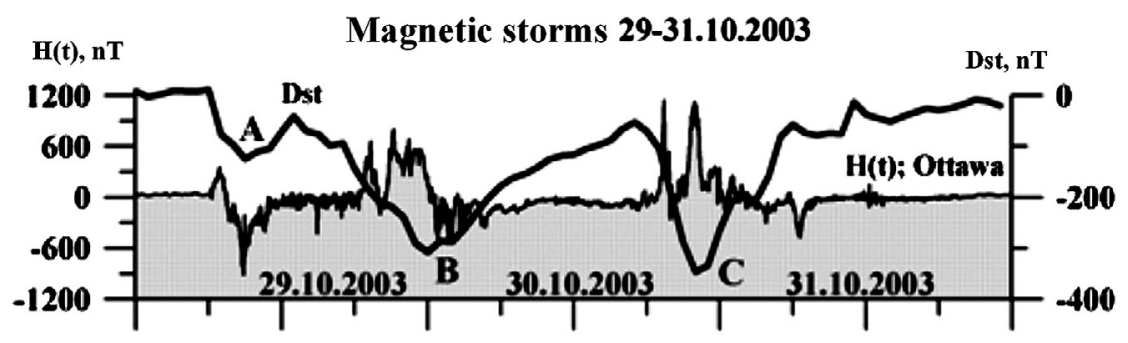

A(t), TECU/1000

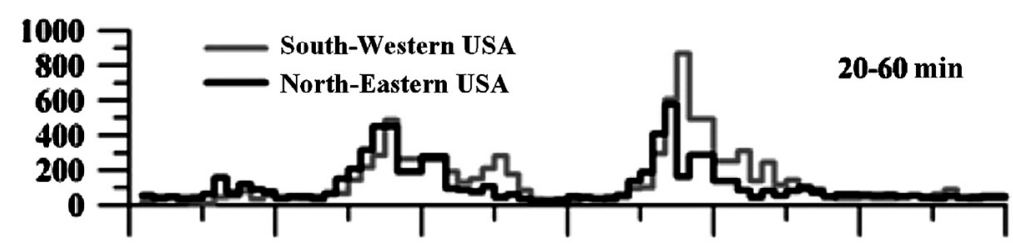

(b)

\section{B(t), TECU/1000}

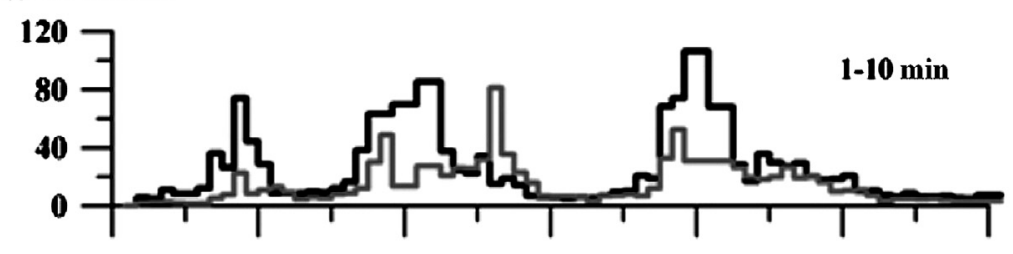

(c)
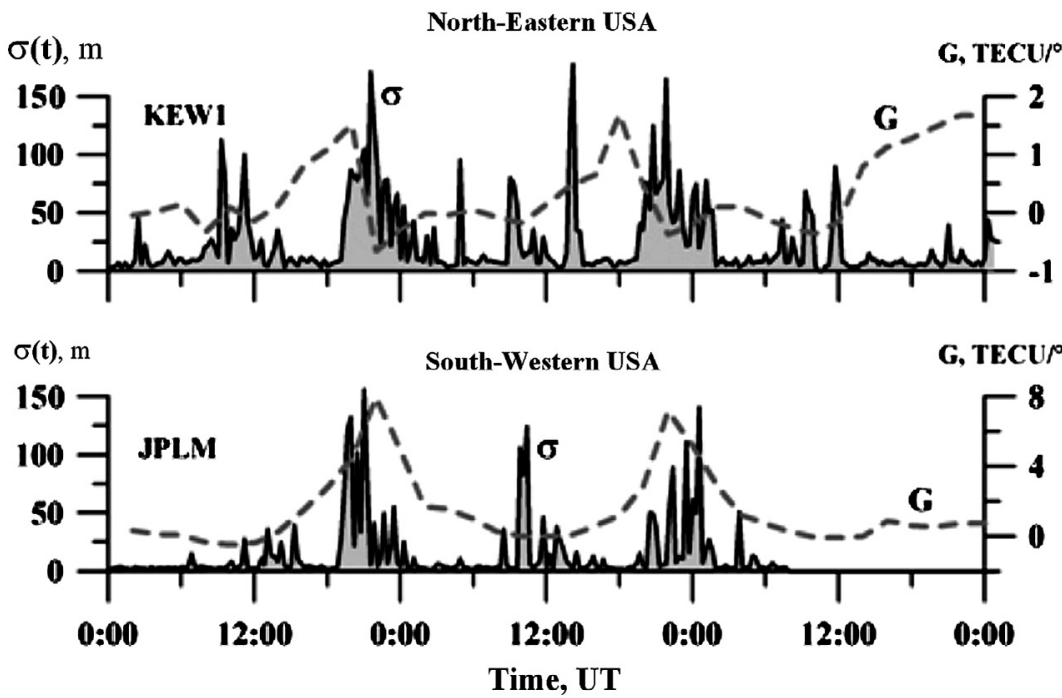

Fig. 7. Errors in GPS positioning during the magnetic storms of 29-31 October 2003 (d, e); variations of geomagnetic parameters (a); rootmean-square deviations of TEC in the range of periods of 20-60 and 1-10 min. (b, c) (figure taken from Afraimovich \& Perevalova 2006).

The reasons for failures of carrier phase tracking can be both decrease in signal level due to ionospheric irregularities and increase in background noise level due to various factors. For instance, a major contribution is made by broadband solar radiation during SFs (Cerruti et al. 2006; Carrano et al. 2007; Afraimovich et al. 2008b, 2009e).

On 6 December 2006, there was a flare whose intensity of radio emission was at least two orders of magnitude higher than that of the known flares. Using data from the global GPS network, phase slips $Q(t)$ at the L2 frequency and count omissions $W(t)$ characterising phase slips at both frequencies were obtained during the most powerful radio bursts (Fig. 9) (Afraimovich et al. 2009e). According to data from all receivers aboard certain satellites, more than 80 percent of measurements were accompanied by slips at both frequencies, responsible for count omissions (Fig. 9c and 9d). The count omissions coincided with degradation of the signal-to-noise ratio (Fig. 9b, according to data from the special-purpose GPS receiver). GPS functioning on the Earth's daylight side was partially disrupted for 5-10 min (Afraimovich et al. 2009e). High accuracy GPS positioning which required reliable signal reception at both frequencies was disrupted at 10-20 percent of stations on the daylight side.

The results of comparison of the stabilities of GPS and GLONASS system operation are presented below. Figure 10 presents dependences of relative density $P(t)$ of failures when measuring parameters of navigation signals L1, C1, L2, P1, P2. Receivers on the daylight side were used for analysis. Grey 
E.L. Afraimovich et al.: A review of GPS/GLONASS studies of the ionospheric response

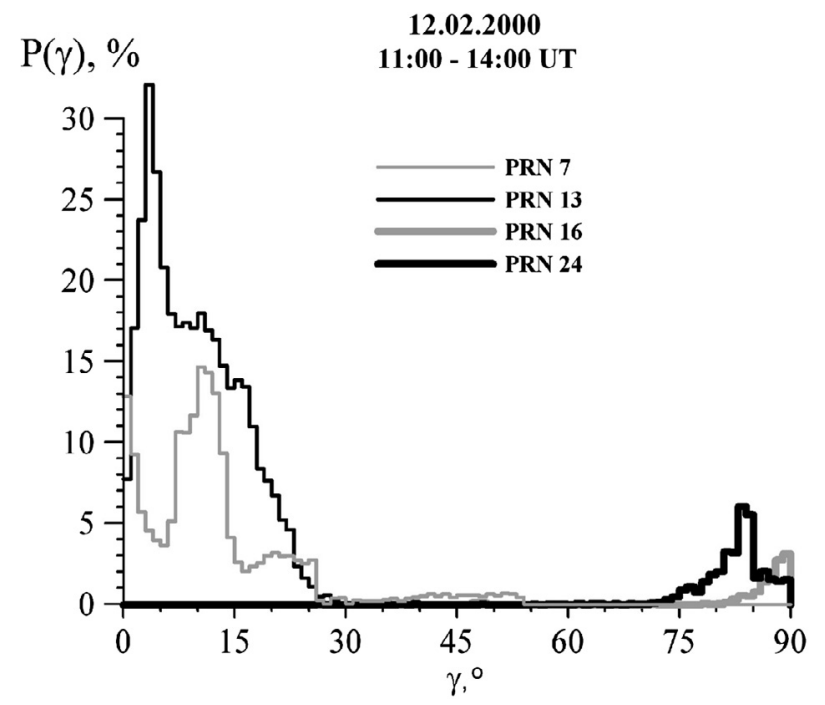

Fig. 8. Dependence of slip density $P(\gamma)$ on the angle $\gamma$ for four GPS satellites (figure taken from Demyanov et al. 2011).

curve depicts average values from all GPS satellites under observation; black curve, from all GLONASS satellites. Presented here are the results for flares of 6 and 13 December 2006. Letters A (6 December) and B (13 December) present time intervals when solar radio emission was more than $10^{6}$ s.f.u. (on 6 December) and $10^{5}$ s.f.u. (on 13 December) (Afraimovich et al. 2008b, 2009e; Demyanov et al. 2013).

Figure 10 shows that measurements of $\mathrm{L} 1$ and $\mathrm{C} 1$ parameters at the main GPS-GLONASS frequency are least subject to failures. At this frequency, the transmitter power is higher. On 6 December, for instance, no failure of $\mathrm{L} 1$ or $\mathrm{C} 1$ was recorded (Fig. 10a). Only on 13 December at 03.34 UT, short-term failures of L1 and $\mathrm{C} 1$ at GPS-GLONASS frequencies were recorded. Besides, the maximum density of failures Qmax for all parameters of GLONASS signals (apart from L1 and C1) were 2-4 times less than for those of GPS signals.

\section{Ionospheric response to tropical cyclones}

Tropical cyclones (TCs) are the powerful tropospheric vortical disturbances. TCs can generate internal atmospheric waves (IAWs) with periods of $1-150 \mathrm{~min}$. IAWs can penetrate into the ionosphere and manifest themselves as travelling ionospheric disturbances (TIDs) (Hocke \& Schlegel 1996; Lastovicka 2006). Using GPS occultation technique Bishop et al. (2006) showed that there is an increase in gravity wave activity and F region scintillation. Mao et al. (2010) using TEC maps showed that TEC of the typhoon region is larger than TEC monthly median of that region, then the increment begins to decline after typhoon landing and becomes below zero a day after landing.

Using GPS data, we made an experimental estimate of the ionospheric response to tropical cyclones (Polyakova \& Perevalova 2011). Three strong TCs which developed along the Atlantic coast of the USA were used: Katrina (from 23 August 2005 to 31 August 2005), Rita (from 18 September 2005 to 26 September 2005) and Wilma (from 15 October 2005 to 25 October 2005). We used phase measurement data from dual-frequency GPS receivers (http://sopac.ucsd.edu) located near the area covered by the said cyclones.
To analyse ionospheric disturbances produced by cyclones, we selected the following time intervals:

- when geomagnetic conditions were quiet;

- when cyclones reached their peak intensity.

We picked out time series of TEC variations obtained in the evening or at night (LT) when the equatorial ionization anomaly (EIA) was absent. This can be explained by the fact that ionospheric irregularities are highly probable in the EIA region. Initial time series of TEC variations were filtered for two periods: 02-20 and 20-60 min. To determine spatial localisation of the disturbances observed, we mapped the TEC variation intensity in the region covered by cyclones. The obtained distributions of TEC disturbances were compared to maps of near-ground meteorological parameters (pressure, meridional and zonal wind speeds). Maps of meteorological parameters were constructed from NCEP/NCAR Reanalysis data (http://www.esrl.noaa.gov/psd).

Figure 11 demonstrates spatial and temporal dynamics of TEC variations with the period of $20-60 \mathrm{~min}$, and variations in near-ground pressure during Katrina. Black lines with variable line weights depict trajectories of ionospheric points for satellites PRN02, PRN04, PRN07, which were observed at 10 GPS stations in the evening/at night (LT). Each point size is proportional to amplitude of TEC variations recorded along the given receiver-satellite path.

We revealed an increase in TEC variations in the range of periods of 2 to $20 \mathrm{~min}$ and of 20 to $60 \mathrm{~min}$. When TC reached its peak intensity, amplitude of recorded TEC disturbances was more than 2.5 times higher than the fluctuation level under undisturbed conditions (Fig. 11b). Intensity of TEC variations was higher along the receiver-satellite paths closest to the cyclone (KYW1 and MIA3, see Fig. 11b). There were almost no TEC variations recorded along the paths remote from the area covered by the cyclone. Intensity of TEC disturbances decreased drastically with wind speed of cyclone decreasing down to $30 \mathrm{~m} / \mathrm{s}$. Amplitude of TEC variations with periods of 20-60 min increased more significantly than that of shortterm (2-20 $\mathrm{min})$ disturbances. Unlike variations with periods of 2-20 min, increase in intensity of long-term TEC disturbances was recorded along the paths remote from the cyclone trajectory (AMC2 and WIL1, see Fig. 11b). This implies that the zone with large-scale TEC disturbances covered a large area. The ionospheric response to TCs Rita and Wilma was found to be significantly weaker than that to TC Katrina.

Thus, a region of ionospheric plasma irregularities appears in the ionosphere above the cyclone trajectory. Radius of the region is about $2000 \mathrm{~km}$ from the cyclone centre when it reaches its peak intensity. Disturbances with long periods cover a large area. The region forms when the cyclone is at hurricane stage; it follows the cyclone and disappears when wind speed of TC is less than $30 \mathrm{~m} / \mathrm{s}$.

\section{lonospheric response to earthquakes}

Earthquakes are known to be a source of atmospheric and ionospheric disturbances. Vertical surface displacements resulting from earthquakes generate shock acoustic waves (SAWs) in the neutral atmosphere; they propagate vertically upwards, and their amplitude increases significantly with height, since the atmospheric density decreases. Upon reaching the ionosphere, SAWs generate disturbances in the ionosphere 


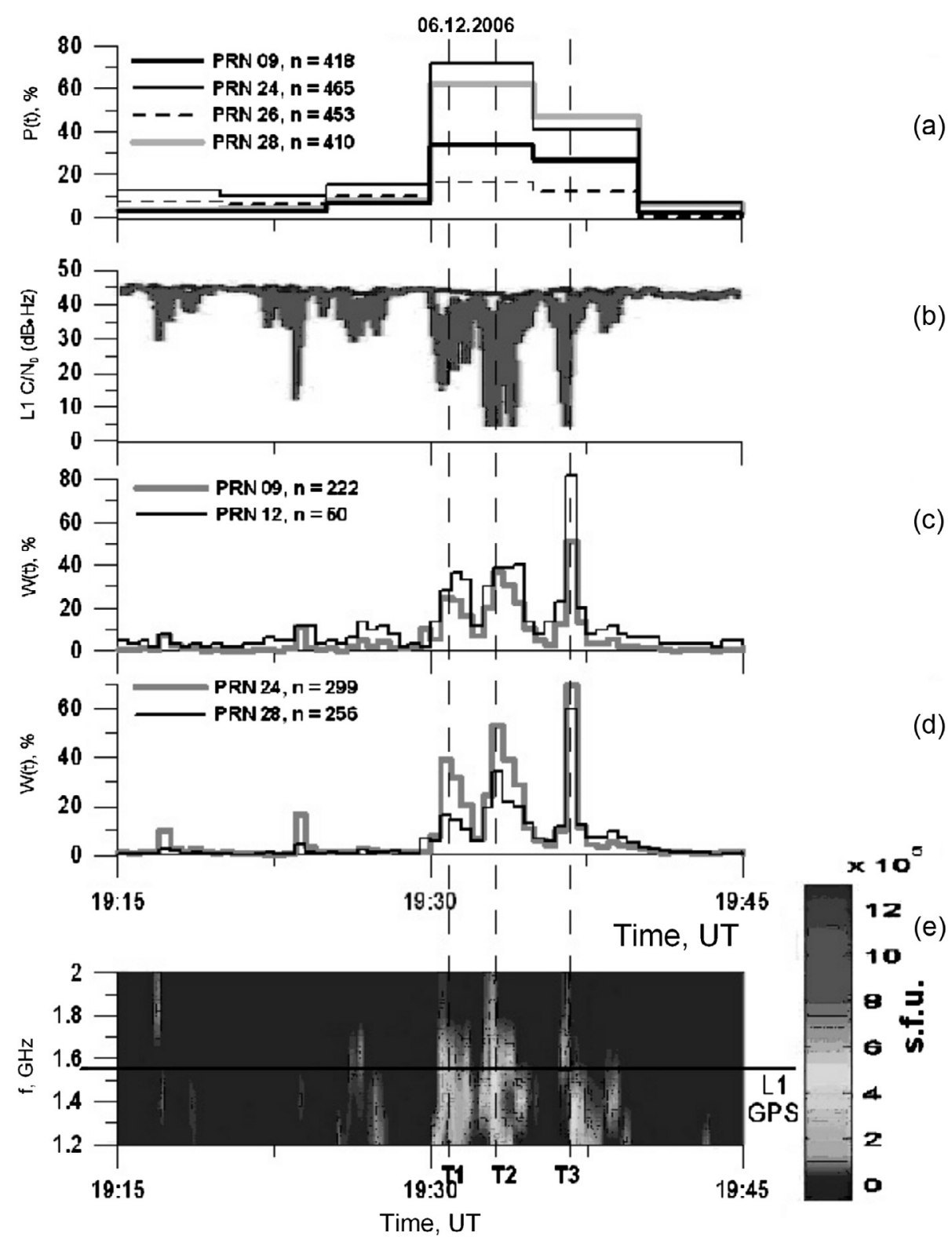

Fig. 9. Phase slips and count omissions for different GPS satellites during the solar flare of 6 December 2006 (a, b, d). Radio spectrum in the range from 1.2 to $2.0 \mathrm{GHz}$, recorded by the solar spectrograph OVSA (e). Signal-to-noise ratio (from Cerruti et al. 2006) at the main GPS frequency fl (b), according to data from the special-purpose GPS receiver aimed at recording GPS signal scintillations (figure taken from Afraimovich et al. 2009e).

(coseismic ionospheric disturbances, CIDs) due to interaction between the neutral and charged components.

Calais et al. (1998) first detected the ionospheric response to earthquakes using GPS. Following Calais et al. (1998), (Afraimovich et al. 2001a, 2006a, 2010a; Astafyeva \& Afraimovich 2006; Astafyeva \& Heki 2009; Astafyeva et al. 2009; Heki 2011; Rolland et al. 2011) conducted a detailed study of the CID spatial and temporal characteristics. According to the theoretical model (Rudenko \& Uralov 1995), acoustic disturbance propagates in a narrow cone of zenith angles from the earthquake epicentre to ionospheric heights and then, in the form of a spherical wave, it propagates at velocities close to the sound speed at these heights. The application of GPS data allowed us to validate this model experimentally for the first time (Afraimovich et al. 2006a). The wave propagation during the 25 September 2003 Tokachi-oki is schematically presented in Figure 12 as an example.
Using the analysis of data after the destructive earthquake of 12 May 2008 in Wenchuan Province (China) as an example, Afraimovich et al. (2010a) have shown that the plane front of TEC disturbances in the ionosphere (at about $500 \mathrm{~km}$ from the source) is parallel to the fault line.

World's densest network of GPS receivers GEONET (Japan) allowed us to analyse the evolution of CID propagating at more than $2000 \mathrm{~km}$. CID was generated by the earthquake of 4 October 1994 near the Kuril Islands and was detected by the nearest GPS receivers $\sim 10 \mathrm{~min}$ after the earthquake. The estimated near-field propagation speed was $\sim 990 \mathrm{~m} / \mathrm{s}$, which is close to the sound speed at ionospheric heights. At a distance of $600-700 \mathrm{~km}$ away from the epicentre, the coseismic perturbation was split into two separate modes (Astafyeva et al. 2009). This two-mode CID propagation is well discernible on the distance-time diagram (Fig. 13). The diagram is plotted from the temporal TEC dependence and from the distance from 
E.L. Afraimovich et al.: A review of GPS/GLONASS studies of the ionospheric response

06.12 .2006
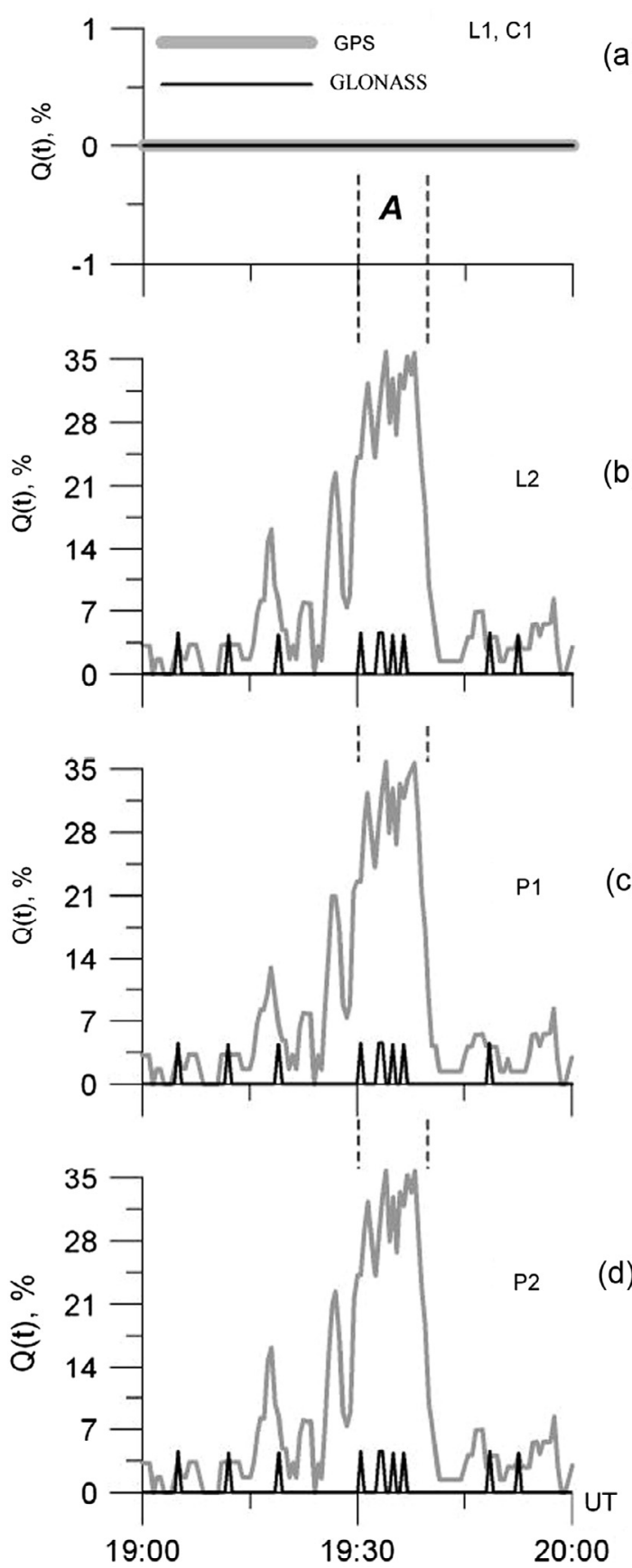

13.12.2006

(a)

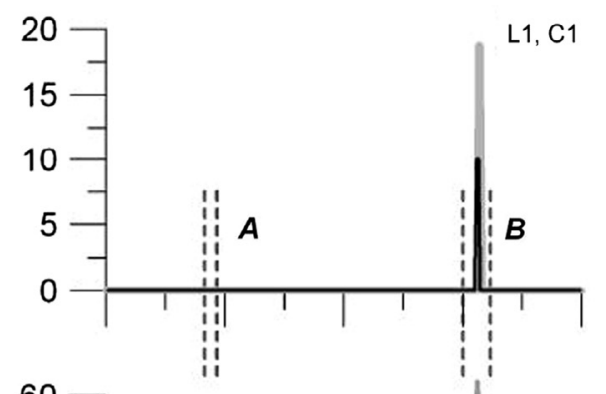

(e)

L2

(f)

(g)

(h)

Fig. 10. Comparison between densities of failures of GPS and GLONASS measurements during the flares on 6 and 13 December 2006 (figure taken from Afraimovich et al. 2009e).

the source (centre of surface uplift) to ionospheric points calculated from the great circle distance. According to Figure 13, the separate modes are characterised by quite different values of propagation velocities: $2.7-3.0 \mathrm{~km} / \mathrm{s}$ (fast mode) and $600-660 \mathrm{~m} / \mathrm{s}$ (slow mode). The fast mode was most likely triggered by the propagation of Rayleigh surface waves, the slow mode corresponds to acoustic waves (Astafyeva et al. 2009).

In the meantime, the TEC response does not always have the form of $\mathrm{N}$-wave (as was previously stated) and is probably dependent on the focal mechanism of an earthquake (Astafyeva \& Heki 2009). Comparative analysis of the ionospheric TEC response to three earthquakes with different focal mechanisms has been conducted (Astafyeva \& Heki 2009). The authors have analysed three events: on 4 October 1994 (Thrust+normal fault), on 15 November 2006 (thrust) and on 13 January 2007 (normal fault). The analysis has shown that the N-shaped TEC response occurs after a thrust-fault earthquake, whereas normal fault earthquake seems to generate the inverse $\mathrm{N}$-wave perturbation.

It should be noted that, a specific generation mechanism of ionospheric disturbances during an earthquake is usually quite a complicated process. It depends on many factors. More 
(a)

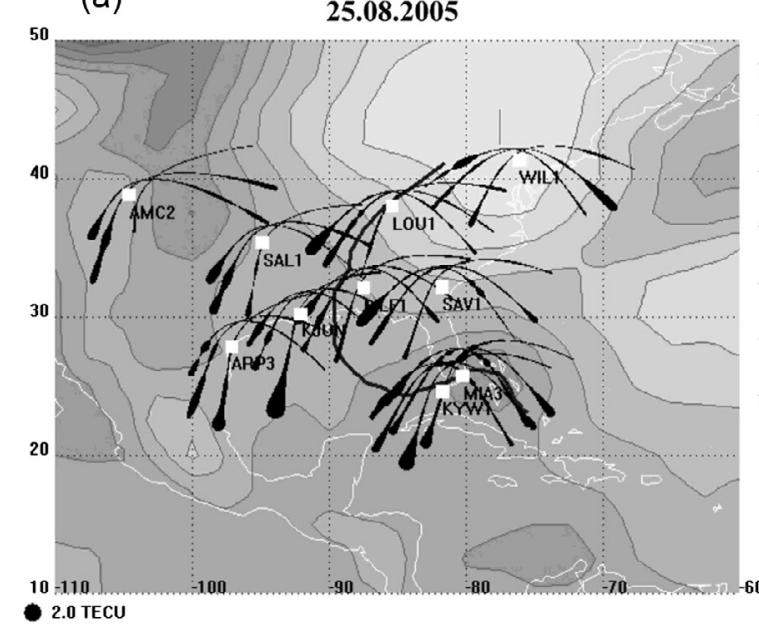

(b)

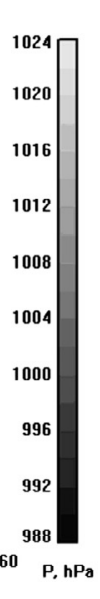

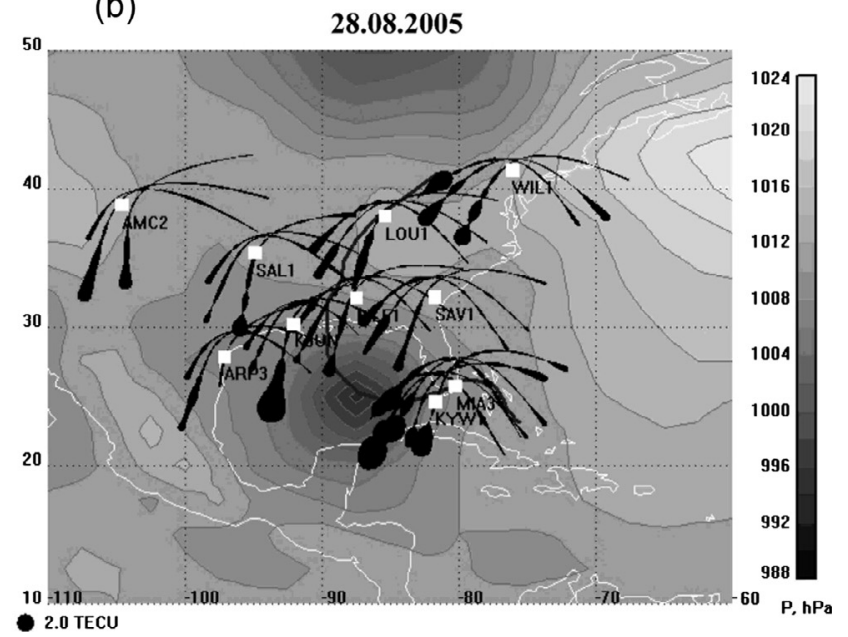

Fig. 11. Spatial distribution of the TEC variation intensity with periods of 20-60 min (black lines with variable line weights) near the area covered by TC Katrina on 25 and 28 August 2005 (figure taken from Polyakova \& Perevalova 2011).

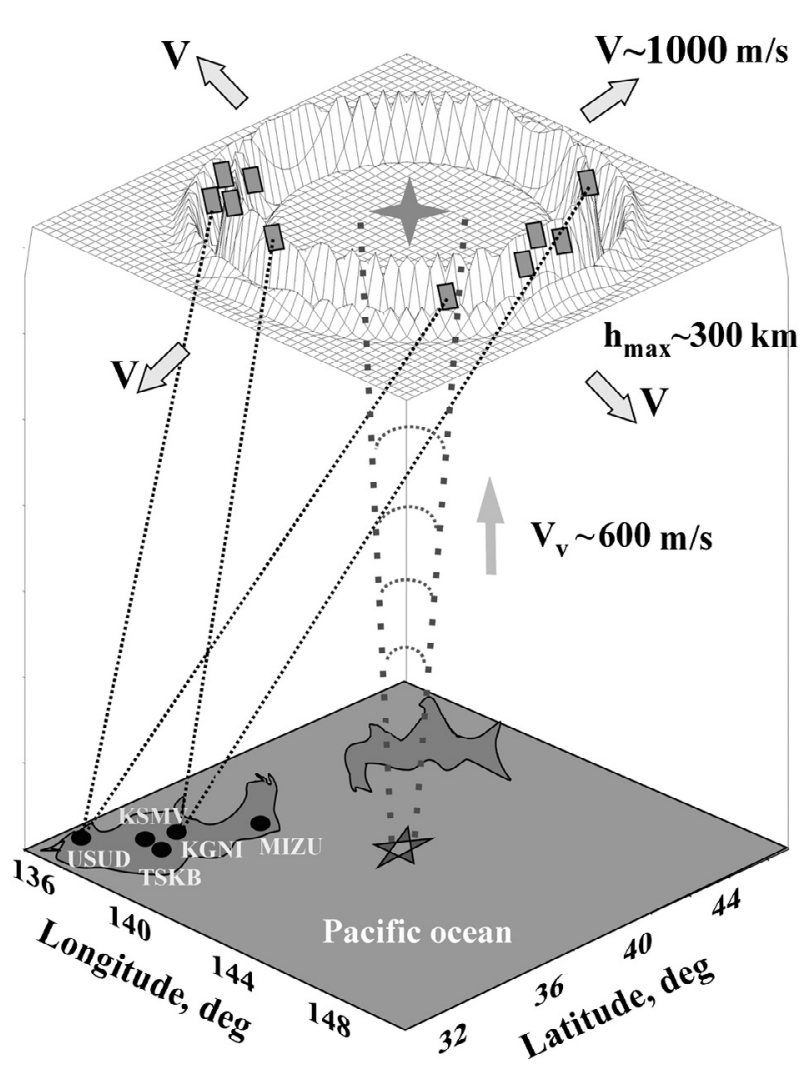

Fig. 12. Pattern of the SAW generation and detection during the earthquake in Japan on 25 September 2003 (figure taken from Afraimovich \& Perevalova 2006).

thorough observations and study of the seismo-ionospheric coupling are thus needed.

Statistics of GPS measurements during earthquakes, space vehicle launches and industrial explosions shows the similarity between SAW ionospheric responses. In certain cases, there may nevertheless be some peculiarities depending on the SAW source origin.

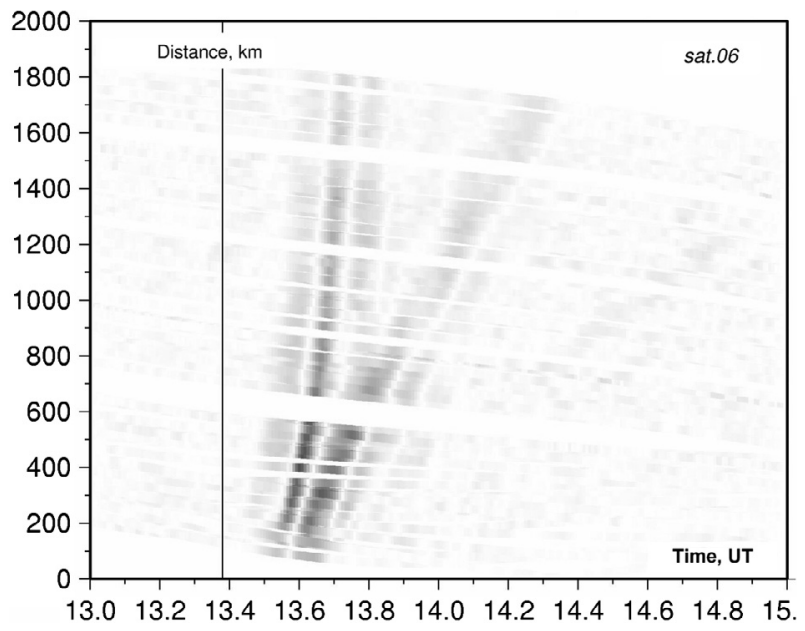

Fig. 13. Time-distance diagram for the seismic ionospheric disturbance. The thin vertical line depicts time of the earthquake (figure taken from Astafyeva et al. 2009).

\section{Ionospheric response to rocket launches}

Analysis of the ionospheric response to rocket launches has a special place in the study of SAWs (Afraimovich \& Kiryushkin 2002; Afraimovich et al. 2002d; Kiryushkin et al. 2008). Such studies are conducted throughout the world (e.g., Ozeki \& Heki 2010). We examined responses to launches of Proton, Soyuz, Dnepr and Zenith rockets from the Baikonur Cosmodrome (Kazakhstan), Space Shuttles from Kennedy Space Center (KSC, USA) and Shenzhou-2 spacecraft from Jiuquan Satellite Launch Center (China) over the period 1998-2001. All rocket launch information was taken from the following websites: http://www.flato-day.com; http://www.spacelaunchnews.com; http://www.ksc.nasa.gov; http://www.isllaunch.com.

Figure 14 exemplifies some launches. Curves depict TEC time dependences $\mathrm{d} I(t)$ after trend removal. Thick curve presents TEC variations on launch day; thin curves correspond to one day before and one day after the launch. On the background of slow TEC variations, one can easily see typical variations determined by the SAW propagation. The SAW 
E.L. Afraimovich et al.: A review of GPS/GLONASS studies of the ionospheric response

Proton (05.07.1999)

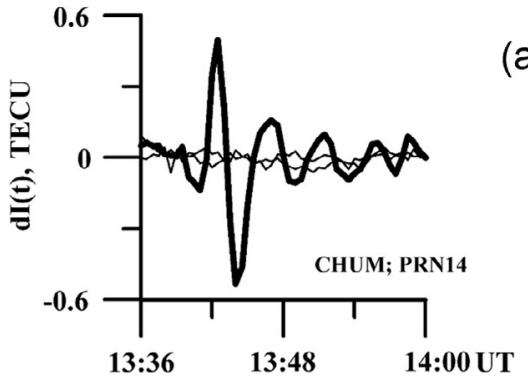

Soyuz (15.04.1999)

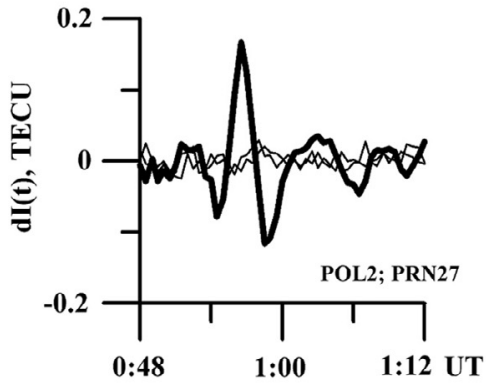

Zenith (03.02.2000)

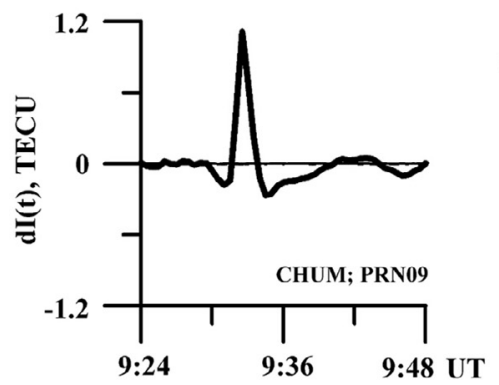

Shuttle (29.10.1998)

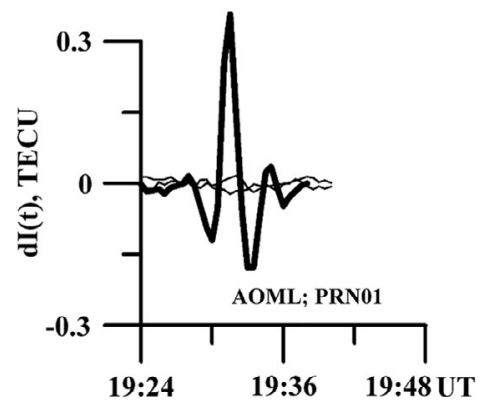

Proton (12.02.2000)

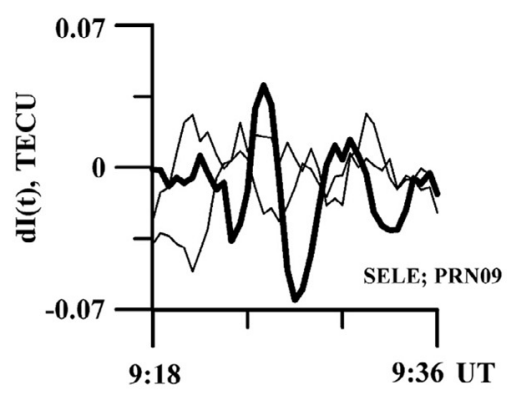

Dnepr (21.04.1999)
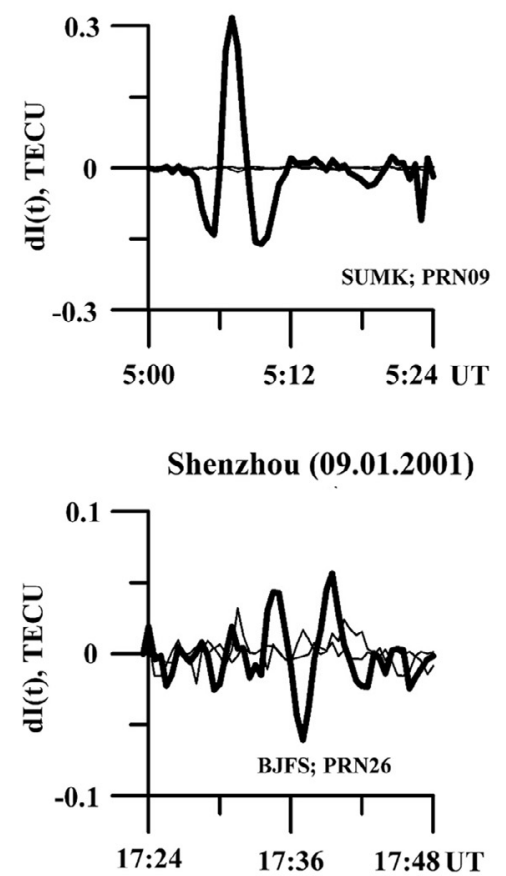

Shuttle (17.04.1998)

(d)

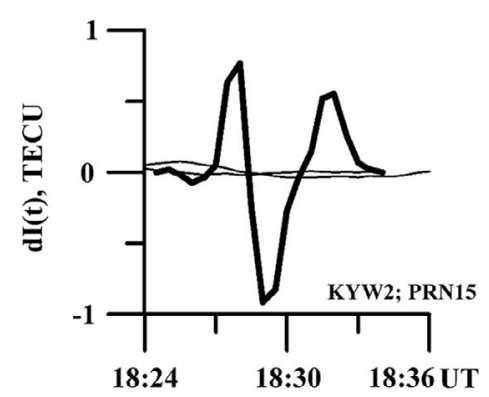

(f)

(g)

(e)

(h)

Fig. 14. TEC variations during space vehicle launches (figure taken from Afraimovich \& Perevalova 2006).

ionospheric response has been found to be a bipolar pulse during all rocket launches. Such a pulse corresponds to the classical N-wave of the shock wave. The response conforms to the SAW pressure profile: positive half-period corresponds to the SAW contraction phase; negative, to the SAW exhaustion phase. The response does not depend on a type of carrier rocket, on local time, season or magnetic activity level.

The experience of studying a large number of rocket launches using the GPS TEC data allows us to state that reliable detection of SAWs generated by space vehicle launches is vir- tually independent of season, time of day or geomagnetic conditions. Thus, probability of detecting disturbances is $\sim 100 \%$.

The recorded responses have the following parameters:

- relative amplitude of TEC variations varies in the range from 0.2 to $2 \%$; this equal variations in local concentration in the F2 layer within $0.6-6 \%$;

- wavelength is from 300 to $1000 \mathrm{~km}$;

- spatial dimensions of the spherical wavefront are up to $2000 \mathrm{~km}$; 
- time period is from 200 to $500 \mathrm{~s}$;

- phase velocity is from 500 to $1200 \mathrm{~m} / \mathrm{s}$.

Relative amplitude of TEC variations was found to be dependent on the angle between wave vector of disturbance and direction of the Earth's magnetic field, and independent of the level of geomagnetic activity.

Our data are in agreement with the mechanism presented in (Li et al. 1994; Calais \& Minster 1996; Nagorsky 1998). These authors believe that the SAW generation occurs when a rocket with operating engine moves in a nearly horizontal direction along the acceleration segment of trajectory (at heights of the lower atmosphere, $100-130 \mathrm{~km}$ ). The rocket travels this segment at supersonic speeds, 100-300 s after the launch. The distance from the launch pad is no less than $500 \mathrm{~km}$. As soon as the rocket reaches the altitude of about $100 \mathrm{~km}$ at supersonic speeds, the SAW source is "switched on".

\section{Large-scale ionospheric disturbances of auroral origin}

A geomagnetic storm is a complicated event in near-Earth space. Researches into LS TIDs with the use of GPS data are conducted all over the world (e.g., Ding et al. 2007). During strong storms, the ionosphere experiences significant changes. Its state depends on many parameters such as season, solar activity phase, time of storm commencement, magnitude of disturbance and state of the ionosphere before storm. Using the GLOBDET complex, characteristics of large-scale travelling ionospheric disturbances (LS TIDs) during 16 strong geomagnetic storms of 1998-2006 were determined (Afraimovich \& Perevalova 2006).

As a result of the magnetic storm, large-scale TEC disturbances occur almost simultaneously in the ionosphere in the Northern and Southern Hemispheres. These disturbances are the solitary waves (Afraimovich et al. 2005). Characteristic duration of LS TIDs is from 30 to $80 \mathrm{~min}$. Extension of the LS TID front exceeds $3000 \mathrm{~km}$. Relative amplitude of the TEC disturbance $\mathrm{d} I / I$ in LS TIDs is from 10 to $14 \%$. Computer simulation was carried out and compared to results of ionosonde measurements. The analysis has revealed that $\mathrm{d} I / I$ (10-14\%) corresponds to relative amplitude of disturbances of the electron density $\mathrm{Ne}$ in the F-layer maximum $\mathrm{dNe} / \mathrm{Ne}$ (about 40-50\%) (Perevalova et al. 2008).

The analysis of experimental data has shown that LS TIDs propagate in the direction close to the equatorial one, to distances up to $4500 \mathrm{~km}$. In the Northern Hemisphere, the propagation azimuth $\alpha$ is from $160^{\circ}$ to $240^{\circ}$; in the Southern, it is about $330^{\circ}$. The horizontal velocity of wave propagation $\mathrm{Vh}$ varies from 300 to $1200 \mathrm{~m} / \mathrm{s}$ and is different for different storms and longitudinal sectors.

Extensive research into form of the wavefront and into velocity of the LS TID propagation was carried out, using the storm of 29 October 2003 as an example (Afraimovich \& Perevalova 2006). In order to determine phase velocity and form of the wavefront in the Northern Hemisphere, all available GPS stations in the Northern Hemisphere were divided into five zones: Western American (A), Eastern American (B), European (C), Eastern Asian (D) and Far Eastern (E) ones (Fig. 15). LS TIDs were found to occur on the southern boundary of the auroral oval after a sudden storm commencement (SSC). Analysis of the spatial distribution of maxima and minima of TEC disturbances revealed that LS TIDs had a ring-shaped front. Centre of the ring was near the North Magnetic Pole (NMP). Velocity and direction of disturbance propagation was dependent on longitude. The lowest speed $(700 \mathrm{~m} / \mathrm{s})$ was recorded in the night-time hemisphere where TEC values were minimum; the highest speed $(1600 \mathrm{~m} / \mathrm{s})$, in the daytime hemisphere where TEC values were maximum. LS TIDs were propagating in the equatorial direction. However, the so-called "swirling" effect of propagation in the direction opposite to the Earth's rotation was found (Perevalova et al. 2008). The swirling is provided by the westward zonal velocity component. In the night and day sectors, the propagation direction was near the meridional one; in the morning and evening sectors, the zonal velocity component was larger than the meridional one (Fig. 15). The westward deviation of the LS TID propagation has been mentioned in other papers (Kvavadze et al. 1988; Balthazor \& Moffett 1999; Hall et al. 1999, Afraimovich et al. 2000). These findings are in agreement with other researcher's findings. The westward swirling of the LS TID wave front was recorded when examining effects of the magnetic storm of 25 September 1998 with the use of data from North American stations (Afraimovich et al. 2000). The wave vector direction varied along the wave front from $245^{\circ}$ (longitude of 16:00 LT) to $177^{\circ}$ (longitude of 19:00 LT). The propagation direction became more and more equatorial when approaching the local night-time. Besides, all authors who present numerical values of the LS TID azimuth point out the westward azimuth deviation of 10-20 (Kvavadze et al. 1988; Balthazor \& Moffett 1999; Hall et al. 1999). Most authors attribute this to the Coriolis effect on the AGW propagation in the atmosphere. The question of reasons for the LS TID travel deviation from the equatorial direction is still open.

Using GPS network data, the theory, according to which the LS TID background gradients $\mathrm{Ne}$ are augmented and the increase in intensity of smaller-scale irregularities accompanies LS TIDs, has been corroborated experimentally for the first time. The magnetic storm of 29-31 October 2003 was studied as an example to verify the hypothesis about generation of small-scale ionospheric irregularities due to the propagation of strong LS TIDs (Afraimovich et al. 2006d). Several GPS stations located in the American sector along the great-circle arc (where LS TIDs were propagating) were used for analysis. TEC variations $\mathrm{d} I(t)$ filtered for the periods of 20-60 and 1-10 $\mathrm{min}$ are presented in Figure 16. LS TIDs were propagating from the Northeastern to the Southwestern USA. In the regions with maximum LS TID amplitude, intensity of $\mathrm{d} I(t)$ within the range of 1-10 min was one order of magnitude higher. This corresponds to amplification of ionospheric plasma irregularities of the scale from 10 to $100 \mathrm{~km}$ or even from 100 to $1000 \mathrm{~m}$, considering the fact that the ionospheric irregularity spectrum is the power law spectrum. As the LS TID amplitude attenuated, amplitude of small-scale disturbances decreased too. This tendency can be observed in other storms as well.

\section{Global electron content}

In 2006, Afraimovich et al. have developed technique and software package for determining global electron content (GEC) 
E.L. Afraimovich et al.: A review of GPS/GLONASS studies of the ionospheric response

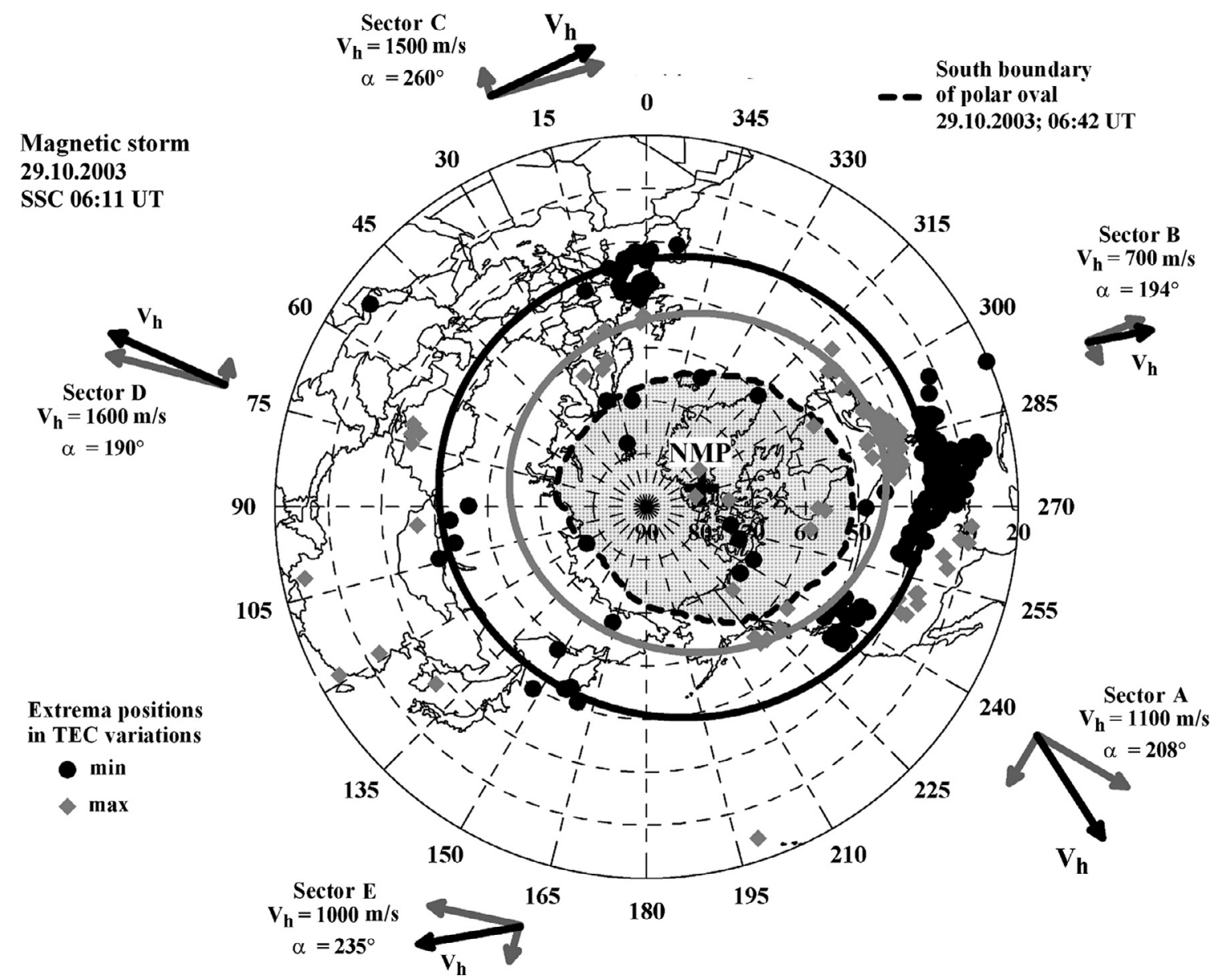

Fig. 15. Form of the wavefront and horizontal velocity of the LS TID propagation during the magnetic storm of 29 October 2003 (figure taken from Perevalova et al. 2008).

29.10.2003; USA

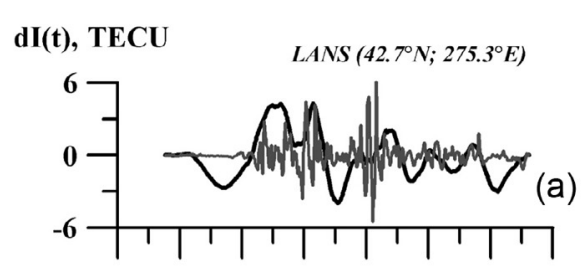

dI(t), TECU

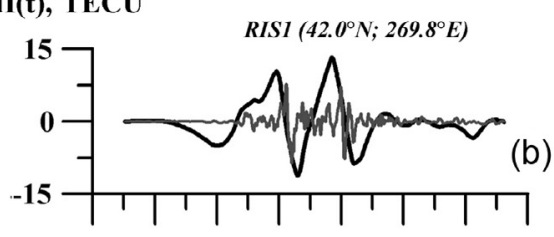

30.10.2003; USA

dI(t), TECU

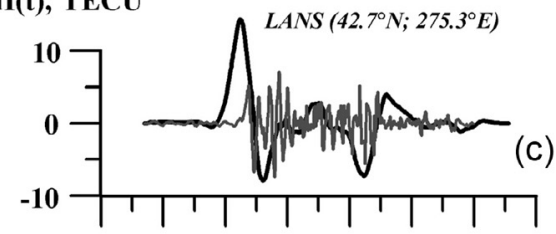

dI(t), TECU

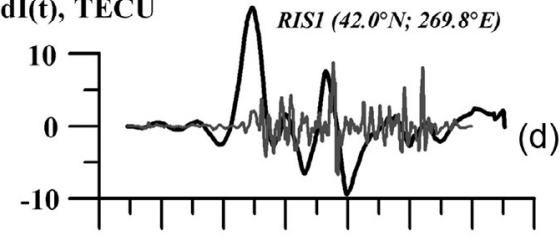

\section{- 20-60 min}

\section{$1-10 \mathrm{~min}$}

Fig. 16. TEC variations on 29 and 30 October 2003, filtered for the periods of 20-60 and 1-10 min (figure taken from Afraimovich et al. 2006d).

(Afraimovich et al. 2006e). GEC equals the total number of electrons in near-Earth space, with the height limitation of about $20000 \mathrm{~km}$ (orbit of GPS satellites). The technique for calculating GEC rests on the GIM technique. The global electron con- tent $G$ is calculated by summing TEC values in each cell (over the set of GIM cells), multiplied by the GIM cell area $S_{i j}$ :

$$
G=\sum I_{\mathrm{AV}}^{i j} S_{i j}
$$




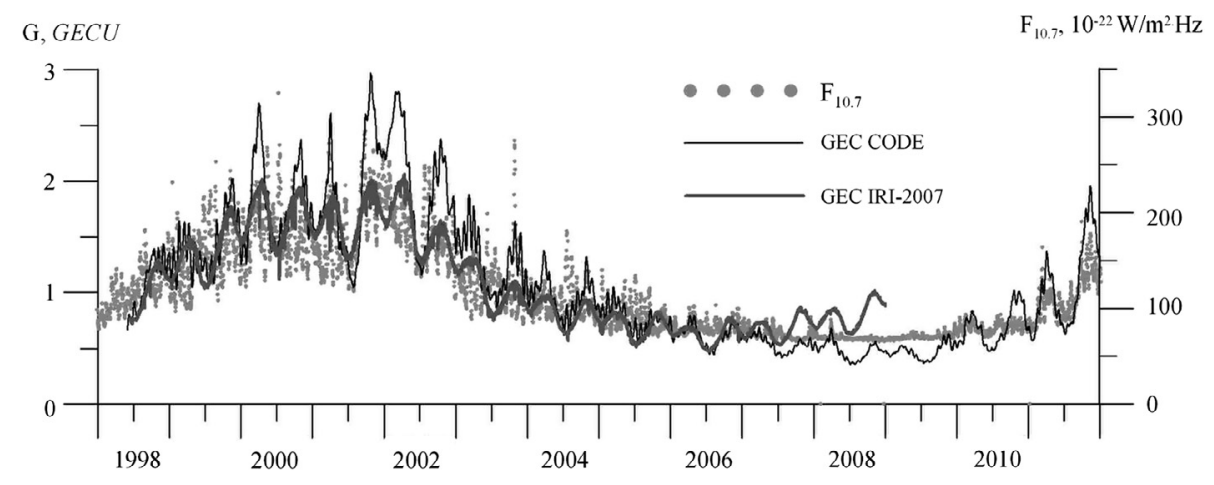

Fig. 17. Dynamics of GEC, F10.7 index and GEC model values in 1998-2010.

where $I_{\mathrm{AV}}^{i j}$ are the values of the absolute vertical TEC, indices $i$ and $j$ denote coordinates (latitude and longitude) of the GIM cell.

The unit GECU ( $10^{32}$ electrons) was introduced to analyse GECs (Afraimovich et al. 2006b). The regional electron content (REC) can be calculated by analogy to GEC. REC is equal to the number of electrons above the given region. In some cases, one may normalise GEC or REC to the surface area in order to determine mean TEC value over the territory (Yasyukevich et al. 2010). This is quite convenient when making comparison with other instruments.

The advantage of using GEC is that local features of ionospheric parameters are smoothed. As a result, regularities that describe state and dynamic regime of the ionosphere can be revealed. GEC values and variations are determined by three main factors: solar activity, magnetospheric processes and processes in the neutral atmosphere. This generalised ionospheric parameter can be thus used as an index which reflects state of near-Earth space. Besides, GEC data can be used to solve inverse problems (to obtain quantitative characteristics of flux of solar UV radiation, etc.).

GEC dynamics during the 23rd solar cycle (1998-2011) is represented by the black curve in Figure 17. One can see significant GEC variations (from 0.5 to $3.2 \mathrm{GECU}$ ) during the 23 solar cycle. GEC adequately reflects solar activity effects on the ionosphere. Comparison between GEC dynamics and time variations of solar radio flux at 10.7-cm wavelength F10.7 (grey dots in Fig. 17) proves this fact. We calculated GEC model values with the use of International Reference Ionosphere IRI-2007 (Bilitza \& Reinisch 2008) (dark-grey curve). One can see quite a good agreement between experimental GEC values and model values.

Papers (Afraimovich et al. 2006b, 2006c, 2008a) have revealed that GEC is characterised by significant seasonal variations (up to $30 \%$ ). Maximum seasonal variations are observed at equinoxes. There are also seasonal variations in GEC ratio in the daytime and night-time hemispheres. They are maximal at the summer and winter solstices.

Twenty-seven-day GEC variations are similar to the corresponding variations in F10.7 and in solar UV radiation (correlation coefficient exceeds 0.9). They are, however, on a 2-day delay on average. Relative amplitude of 27 -day variations fluctuates from $8 \%$ (when solar activity goes up and down) to $2 \%$ (at solar maximum). This corresponds to dynamics of active solar features during an 11-year cycle. Comparison with the IRI model has revealed that simulation results correlate well with experimental values. There are, however, some differences. There is difference of 20-40 days (with some delay or lead) between the phase of seasonal variations in the model and in experimental values.

Thus, GEC data are of interest for specifying ionospheric models and mutual verification of global ionospheric maps calculated at various research centres.

In (Afraimovich \& Astafyeva 2008), GEC and REC were used to verify hypothesis about disruption of diurnal TEC variations in the region of the imminent earthquake. Anomalies previously attributed to earthquakes were found to be not local. They are due to the global increase in ionisation throughout the world.

The technique for calculating GEC was developed by K. Hocke (Institute of Applied Physics, University of Bern, Bern, Switzerland) (Hocke 2008). It is used to analyse ionospheric variations of different periods, as well as global response of the ionosphere to solar flares.

\section{Conclusion}

The GPS technique allows analysing different effects on the state of ionospheric plasma. This technique can be used to analyse the state of near-Earth space and the spectrum and composition of disturbances, which generate the ionospheric response, in more detail. GPS data can also be used to detect unauthorised launches of space vehicles. Developments in GNSS, improvements in receiving technology, and expansion of global and regional networks will allow us to improve the accuracy, precision, and reliability of the observations, and thus contribute to both the ionospheric research and its applications.

On 8 November 2009, Prof. Edward L. Afraimovich, leader of our working group, passed away. This article is dedicated to his memory.

Acknowledgements. We are very thankful to I.F. Gamayunov, V.A. Karachentsev, V.V. Kiryushkin, T.N. Kondakova, A.V. Plotnikov, P.V. Tatarinov, I.I. Ushakov for their active assistance. We are thankful to the referees who have enabled us to improve the manuscript through their valuable suggestions. The study was partially supported by RFBR (under Grants Nos. 12-05-33032 a, 12-05-31279 a and 12-05-31069 a), by the Ministry of Education and Science of the Russian Federation (under agreement Nos. 8699, 8388 and 14.518.11.7065), and by the Russian Federation President Grant MK-3771.2013.5. 


\section{References}

Aarons, J., Development of high latitude phase fluctuations during the January 10, April 10-11, and May 15, 1997 magnetic storms, J. Atmos. Sol. Terr. Phys., 61 (34), 309-327, 1999.

Afraimovich, E.L., The GPS global detection of the ionospheric response to solar flares, Radio Sci., 35 (6), 1417-1424, 2000.

Afraimovich, E.L., First GPS-TEC evidence of wave structure excited by solar terminator moving, Earth, Planets, Space, 60, 895-900, 2008.

Afraimovich, E.L., and E.I. Astafyeva, TEC anomalies - local TEC changes prior to earthquakes or TEC response to solar activity changes? Earth, Planets, Space, 60, 961-966, 2008.

Afraimovich, E.L., and V.V. Kiryushkin, Space-multichannel reception for ionosphere monitoring during launches, Quantum Electron. Radio Phys., 11, 46-53, 2002.

Afraimovich, E.L., and N.P. Perevalova, GPS monitoring of the Earth's upper atmosphere, SC RRS SB RAMS, Irkutsk, Russia, Irkutsk, Russia, p. 480 (in Russian), ISBN: 5-98277-033-7, 2006.

Afraimovich, E.L., K.S. Palamartchouk, N.P. Perevalova, V.V. Chernukhov, A.V. Lukhnev, and V.T. Zalutsky, Ionospheric effects of the solar eclipse of March 9, 1997, as deduced from the GPS data, Geophys. Res. Lett, 25 (4), 465-468, 1998.

Afraimovich, E.L., E.A. Kosogorov, L.A. Leonovich, K.S. Palamarchouk, N.P. Perevalova, and O.M. Pirog, Determining parameters of large-scale traveling ionospheric disturbances of auroral origin using GPS-arrays, J. Atmos. Sol. Terr. Phys., 62 (7), $553-565,2000$.

Afraimovich, E.L., N.P. Perevalova, A.V. Plotnikov, and A.M. Uralov, The shock-acoustic waves generated by the earthquakes, Ann. Geophys., 19 (4), 395-409, 2001a.

Afraimovich, E.L., A.T. Altyntsev, E.A. Kosogorov, N.S. Larina, and L.A. Leonovich, Ionospheric effects of the solar flares of September 23, 1998 and July 29, 1999 as deduced from global GPS network data, J. Atmos. Sol. Terr. Phys., 63 (17), 1841-1849, $2001 \mathrm{~b}$.

Afraimovich, E.L., E.A. Kosogorov, and O.S. Lesyuta, Effects of the August 11, 1999 total solar eclipse as deduced from total electron content measurements at the GPS network, J. Atmos. Sol. Terr. Phys., 64, 1933-1941, 2002a.

Afraimovich, E.L., A.T. Altynsev, V.V. Grechnev, and L.A. Leonovich, The response of the ionosphere to faint and bright solar flares as deduced from global GPS network data, Ann. Geophys., 45 (1), 31-40, 2002b.

Afraimovich, E.L., O.S. Lesyuta, I.I. Ushakov, and S.V. Voeykov, Geomagnetic storms and the occurrence of phase slips in the reception of GPS signals, Ann. Geophys., 45 (1), 55-71, 2002c.

Afraimovich, E.L., E.A. Kosogorov, and A.V. Plotnikov, Acoustic shock waves generated by launches and earthquakes, Cosmic Res., 40 (3), 261-275 (in Russian), 2002d.

Afraimovich, E.L., N.P. Perevalova, and S.V. Voyeikov, Traveling wave packets of total electron content disturbances as deduced from global GPS network data, J. Atmos. Sol. Terr. Phys., $65(\mathbf{1 1} / \mathbf{1 3}), 1245-1262,2003$.

Afraimovich, E.L., E.I. Astafieva, O.I. Berngardt, O.S. Lesyuta, V.V. Demyanov, T.N. Kondakova, and B.G. Shpynev, Mid-latitude amplitude scintillation of GPS signals and GPS performance slips at the auroral oval boundary, Radiophys. Quantum Electron., 47 (7), 453-468, 2004

Afraimovich, E.L., S.V. Voeykov, and I.V. Zhivet'evThe ionosphere response to the sudden storm commencement on October 29, 2003 from GPS networks data, Proc. URSI GA-2005, GP1G01.1(0246), 2005.

Afraimovich, E.L., E.I. Astafieva, and V.V. Kiryushkin, Localization of the source of ionospheric disturbance generated during an earthquake, Int. J. Geomag. Aeron., 6, GI2002, DOI: $10.1029 / 2004 \mathrm{GI} 000092,2006 \mathrm{a}$.

Afraimovich, E.L., E.I. Astafyeva, A.V. Oinats, Yu.V. Yasukevich, and I.V. Zhivetiev, Global electron content as a new index of solar activity. Comparison with IRI modeling results, IRI News, 13 (1), A5, 2006b.

Afraimovich, E.L., E.I. Astafyeva, A.V. Oinats, Yu.V. Yasukevich, and I.V. Zhivetiev, Global electron content and solar activity: comparison with IRI modeling results, Proc. of IGS2006, 8-11 May, Darmstadt, http://nng.esoc.esa.de/ws2006/ Papers/p_Afrai-movich_GEC_IRI_IGS_update.pdf.gz, 2006c.

Afraimovich, E.L., E.I. Astafieva, and S.V. Voeykov, Generation of ionospheric irregularities upon propagation of a solitary internal gravity wave during the major magnetic storm of October 29-31, 2003, Radiophys. Quantum Electron., 49 (2), 79-92, 2006d.

Afraimovich, E.L., E.I. Astafyeva, and I.V. Zhivetiev, Solar activity and global electron content, Dokl. Earth Sci., 409A (6), 921-924, $2006 \mathrm{e}$

Afraimovich, E.L., S.V. Voeykov, N.P. Perevalova, V.V. Vodyannikov, G.I. Cordienko, Yu.G. Litvinov, and A.F. Yakovets, Ionospheric effects of the solar eclipse of the March 29, 2006 over Kazakhstan, Geomag. Aeron., 47 (4), 461-469, 2007.

Afraimovich, E.L., E.I. Astafyeva, A.V. Oinats, Y.V. Yasukevich, and I.V. Zhivetiev, Global electron content: a new conception to track solar activity, Ann. Geophys., 26, 335-344, 2008a.

Afraimovich, E.L., V.V. Demyanov, A.B. Ishin, and G.Ya. Smolkov, Powerful solar radio bursts as the global and free tool for testing satellite broadband radio systems, including GPS-GLONASSGALILEO, J. Atmos. Sol. Terr. Phys., 70, 1985-1994, 2008b.

Afraimovich, E.L., I.K. Edemsky, S.V. Voeykov, Y.V. Yasukevich, and I.V. Zhivetiev, First GPS-TEC imaging of the space structure of MS wave packets excited by the solar terminator, Ann. Geophys., 27, 1521-1525, 2009a.

Afraimovich, E.L., I.K. Edemskiy, S.V. Voeykov, Yu.V. Yasukevich, and I.V. Zhivetiev, Spatio-temporal structure of the wave packets generated by the solar terminator, Adv. Space Res., 44, 824-835, DOI: 10.1016/j.asr.2009.05.017, 2009b.

Afraimovich, E.L., I.K. Edemskiy, A.S. Leonovich, L.A. Leonovich, S.V. Voeykov, and Ya.V. Yasyukevich, The MHD nature of nighttime MSTIDs excited by the solar terminator, Geophys. Res. Lett., 36, L15106, 2009c.

Afraimovich, E.L., E.I. Astafieva, V.V. Demyanov, and I.F. Gamayunov, Mid-latitude amplitude scintillation of GPS signals and GPS performance slips, Adv. Space Res., 43, 964-972, 2009d.

Afraimovich, E.L., V.V. Demyanov, N.S. Gavrilyuk, A.B. Ishin, and G.Ya. Smolkov, Malfunction of satellite navigation systems GPS and GLONASS caused by powerful radio emission of the sun during flares on December 6 and 13, 2006, and October 28, 2003, Cosmic Res., 47 (2), 126-137, 2009e.

Afraimovich, E.L., S.V. Voeykov, and I.K. Edemskiy, Ionosphere effects of total solar eclipse at July 22, 2009 by data of dense GPS network in Japan (GEONET), Proceedings of up-to-date aspects of remote sounding conference. Physical basics, methods and technologies of environment and potentially dangerous phenomena and objects monitoring, 7 (3), 94-98 (in Russian), 2010a.

Afraimovich, E., D. Feng, V. Kiryushkin, E. Astafyeva, S. Jin, and V.A. Sankov, TEC response to the 2008 Wenchuan earthquake in comparison with other strong earthquakes, Int. J. Remote Sens., 31 (13), 3601-3613, DOI: 10.1080/01431161003727747, 2010b.

Afraimovich, E.L., A.B. Ishin, M.V. Tinin, Y.V. Yasyukevich, and S.G. Jin, First evidence of anisotropy of GPS phase slips caused by the mid-latitude field-aligned ionospheric irregularities, $A d v$. Space Res., 47, 1674-1680, 2011.

Anderson, P.C., and P.R. Straus, Magnetic field orientation control of GPS occultation observations of equatorial scintillation, Geophys. Res. Lett., 32, DOI: 10.1029/2005GL023781, 2005.

Astafyeva, E.I., and E.L. Afraimovich, Long-distance propagation of traveling ionospheric disturbances caused by the great SumatraAndaman earthquake on 26 December 2004, Earth, Planets, Space, 58, 1025-1031, 2006.

Astafyeva, E., and K. Heki, Dependence of waveform of near-field coseismic ionospheric disturbances on focal mechanisms, Earth, Planet, Space, 61, 939-943, 2009. 
Astafyeva, E., K. Heki, E. Afraimovich, V. Kiryushkin, and S. Shalimov, Two-mode long-distance propagation of coseismic ionosphere disturbances, J. Geophys. Res., 114, A10307, DOI: 10.1029/2008JA013853, 2009.

Balthazor, R.L., and R.J. Moffett, Morphology of large-scale traveling atmospheric disturbances in the polar thermosphere, $J$. Geophys. Res., 104 (A1), 15-24, 1999.

Beach, T., and K.M. Groves, Ionospheres scintillation monitoring and mitigation using a software GPS receiver, Radio Sci., 9, RS1S21, DOI: 10.1029/2002RS002812, 2004.

Béniguel, Y., B. Forte, S.M. Radicella, H.J. Strangeways, V.E. Gherm, and N.N. Zernov, Scintillations effects on satellite to Earth links for telecommunication and navigation purposes, Ann. Geophys., 47 (2/3), 1179-1199, 2004.

Bilitza, D., and B.W. Reinisch, International reference ionosphere 2007: Improvements and new parameters, Adv. Space Res., 42, 599-609, 2008.

Bishop, R.L., N. Aponte, G.D. Earle, M. Sulzer, M.F. Larsen, and G.S. Peng, Arecibo observations of ionospheric perturbations associated with the passage of Tropical Storm Odette, J. Geophys. Res., 111, A11320, DOI: 10.1029/2006JA011668, 2006.

Calais, E., and J.B. Minster, GPS detection of ionospheric perturbations following a Space Shuttle ascent, Geophys. Res. Lett., 23 , 1897-1900, 1996.

Calais, E., J.B. Minster, and J. Bernard, GPS, earthquake, the ionosphere and space shuttle, Phys. Earth Planet, 105, 167-181, 1998.

Campos de Rezende, L.F., Study on the prediction of ionosphere scintillation using data mining, Proceedings of the International Beacon Satellite Symposium, June 11-15, Boston, 2007.

Carrano, C.S., K.M. Groves, and C.T. Bridgwood, Effects of the December 2006 solar radio bursts on the GPS receivers of the AFRL-SCINDA network, in: Proceedings of the International Beacon Satellite Symposium, June 11-15, edited by P.H. Doherty, Boston College, Boston, 2007.

Cerruti, A.P., P.M. Kintner, D.E. Gary, L.J. Lanzerotti, E.R. de Paula, and H.B. Vo, Observed solar radio burst effects on GPS/WAAS carrier-to-noise ration, Space Weather, 4, S10006, DOI: 10.1029/2006SW000254, 2006.

Conker, R.S., M.B. El-Arini, C.J. Hegarty, and T. Hsiao, Modeling the effects of ionospheric scintillation on GPS/SBAS availability, Radio Sci., 38 (1), DOI: 10.1029/2000RS002604, 2003.

Cot, C., and H. Teitelbaum, Generated of the gravity waves by inhomogeneous heating of the atmosphere, J. Atmos. Terr. Phys., $42(\mathbf{9} / \mathbf{1 0}), 877-883,1980$

Datta-Barua, S., P.H. Doherty, and S.H. Delay, Ionospheric scintillation effects on single and dual frequency GPS positioning, private communication at ION GPS/GNSS 2003, Inst. of Navig., Portland, Oreg., Available from: http://waas.stanford.edu/ wwu/ papers/gps/PDF/DattaBaruaIONGPS03.pdf, 2003.

Demyanov, V.V., Yu.V. Yasyukevich, A.B. Ishin, and E.I. Astafyeva, Effects of ionosphere super-bubble on the GPS positioning performance depending on the orientation relative to geomagnetic field, DOI: 10.1007/s10291-011-0217-9, 2011.

Demyanov, V.V., Yu.V. Yasyukevich, and S. Jin, Effects of solar radio emission and ionospheric irregularities on GPS/GLONASS performance, in: Book Geodetic Sciences - Observations, Modeling and Applications, edited by Prof. Jin Shuanggen, pp. 177222, InTech, ISBN: 978-953-51-1144-3, Available from: http:// www.intechopen.com/books/geodetic-sciences-observations-mod eling-and-applications/effects-of-solar-radio-emission-and-ionosphericirregularities-on-gps-glonass-performance, 2013

Ding, F., W. Wan, B. Ning, and M. Wang, Large scale traveling ionospheric disturbances observed by GPS TEC during the magnetic storm of October 29-30, 2003, J. Geophys. Res., 112, A06309, DOI: 10.1029/2006JA012013, 2007.

Donnelly, R.F., Extreme ultraviolet flashes of solar flares observed via sudden frequency deviations experimental results, Solar. Phys., 20 (1), 188-203, 1971.
Drobjev, V.I., M.Z. Kaliev, Yu.G. Litvinov, B.D. Chakenov, and A.F. Yakovets, On the spatial coherence of the traveling ionospheric disturbances, Geomag. Aeron., 31 (3), 423-426 (in Russian), 1991.

Hall, G.E., J.W. MacDougall, J.-F. Cecile, D.R. Moorcroft, and J.P. St.-Maurice, Finding gravity wave source positions using the Super Dual Auroral Radar Network, J. Geophys. Res., 104 (A1), 67-78, 1999.

Heki, K., Ionospheric electron enhancement preceding the 2011 Tohoku-Oki earthquake, Geophys. Res. Lett., 38, L17312, DOI: 10.1029/2011GL047908, 2011.

Hernández-Pajares, M., J.M. Juan, and J. Sanz, New approaches in global ionospheric determination using ground GPS data, $J$. Atmos. Sol. Terr. Phys., 61, 1237-1247, 1999.

Hocke, K., Oscillations of global mean TEC, J. Geophys. Res., 113, A04302, DOI: 10.1029/2007JA012798, 2008.

Hocke, K., and K. Schlegel, A review of atmospheric gravity waves and traveling ionospheric disturbances: 1982-1995, Ann. Geophys., 14, 917-940, 1996.

Hofmann-Wellenhof, B., H. Lichtenegger, and J. Collins, Global Positioning System: Theory and Practice, Springer-Verlag, Wien, New York, p. 327, 1992.

Huba, J.D., and G. Joyce, Ion sound wave in the topside low latitude ionosphere, Geophys. Res. Lett., 27 (19), 3181-3184, 2000.

Ishin, A.B., E.L. Afraimovich, M.V. Tinin, and Y.V. Yasyukevich, Experimental research of GPS signal scattering by magnetic field oriented irregularities, Proceedings of XI Young Scientists conference "Helio- and geophysical research". Baikal summer International school on basics physics, Publishers, ISTP SB RAS, pp. 87-90 (in Russian), 2009.

Kintner, P.M., H. Kil, and E. de Paula, Fading time scales associated with GPS signals and potential consequences, Radio Sci., 36, 6731-6743, 2001.

Kintner Jr., T. Humphreys, P.M., and J. Hinks, GNSS and ionospheric scintillation - How to survive the next solar maximum", Inside GNSS, 22-29, 2009.

Kiryushkin, V.V., E.L. Afraimovich, and A.A. Disenov, GPSmonitoring of ionospheric disturbances generated during the rockets launching, on the large distances from a launch site, Geomag. Aeron., 48 (3), 352-366, 2008.

Kunitsyn, V.E., E.D. Tereshchenko, and E.S. Andreeva, Ionospheric Radio Tomography, Nauka Moscow, Russia., ISBN 5-02000250-X (in Russian), 2007.

Kvavadze, N.D., Z.L. Liadze, N.V. Mosashvili, and Z.S. Sharadze, Spread-F and the drift of small-scale inhomogeneities in the nighttime $\mathrm{F}$ region of the mid-latitude ionosphere, Geomag. Aeron., 28, 117-118, 1988 .

Lastovicka, J., Forcing of the ionosphere by waves from below, $J$. Atmos. Sol. Terr. Phys., 68, 479-497, 2006.

Le, H., L. Liu, X. Yue, and W. Wan, The ionospheric behavior in conjugate hemispheres during the 3 October 2005 solar eclipse, Ann. Geophys., 27, 179-184, 2009a.

Le, H., L. Liu, X. Yue, W. Wan, and B. Ning, Latitudinal dependence of the ionospheric response to solar eclipses, J. Geophys. Res., 114, A07308, DOI: 10.1029/2009JA014072, 2009b.

Ledvina, B.M., J.J. Makela, and P.M. Kintner, First Observations of Intense GPS L1 Amplitude Scintillations at multitude, Geophys. Res. Lett., 29 (14), 1659-1662, DOI: 10.1029/2002GL014770, 2002.

Leonovich, L.A., and A.V. Taschilin, Disturbances in the top side ionosphere during solar flares, Geomag. Aeron., 48 (6), 759-767, 2008.

Leonovich, L.A., and A.V. Taschilin, Aeronomic effects of solar flares in the topside ionosphere, Earth, Planets, Space, 61, 643648, 2009.

Leonovich, L.A., E.L. Afraimovich, E.B. Romanova, and A.V. Taschilin, Estimating the contribution from different ionospheric regions to the TEC response to the solar flares using data from the international GPS network, Ann. Geophys., 20, 1935-1941, 2002. 


\section{E.L. Afraimovich et al.: A review of GPS/GLONASS studies of the ionospheric response}

Leonovich, L.A., A.V. Taschilin, and O.Yu. Portnyagina, Geomag. Aeron., 50 (2), 201-210, 2010.

Li, Y.Q., A.R. Jacobson, R.C. Carlos, R.S. Massey, Y.N. Taranenko, and $\mathrm{G}$. $\mathrm{Wu}$, The blast wave of the Shuttle plume at ionospheric heights, Geophys. Res. Lett., 21, 2737-2740, 1994.

Liu, J.Y., C.S. Chiu, and C.H. Lin, The solar flare radiation responsible for sudden frequency deviation and geomagnetic fluctuation, J. Geophys. Res., 101, 10855-10862, 1996.

Liu, J.Y., C.H. Lin, H.F. Tsai, and Y.A. Liou, Ionospheric solar flare effects monitored by the ground-based GPS receivers: theory and observation, J. Geophys. Res., 109, A01307, DOI: 10.1029/2003JA009931, 2004.

Ma, G., and T. Maruyama, A super bubble detected by dense GPS network at east Asian longitudes, Geophys. Res. Lett., 33, L21103, DOI: 10.1029/2006GL027512, 2006.

Mannucci, A.J., C.M. Ho, and U.J. Lindqwister, A global mapping technique for GPS-derived ionospheric TEC measurements, Radio Sci., 33 (8), 565-582, 1998.

Mao, T., J. Wang, G. Yang, T. Yu, J. PING, and Y. Suo, Effects of typhoon Matsa on ionospheric TEC, Chin. Sci. Bull., 55 (8), 712 717, DOI: 10.1007/s11434-009-0472-0, 2010.

Meggs, R.W., C.M. Mitchell, and F. Honary, GPS scintillation over the european arctic during the November 2004 storms, GPS Solution., 12 (4), 281-287, 2008.

Mendillo, M., J.A. Klobuchar, R.B. Fritz, A.V. da Rosa, L. Kersley, et al., Behavior of the ionospheric $\mathrm{F}$ region during the greatest solar flare of August 7, 1972, J. Geophys. Res., 79 (4), 665-672, 1974

Mitra, A.P., Ionospheric Effects of Solar Flares, Astrophysics and Space Science Library, D. Reidel publishing Company, Boston, pp. 46-1974, 1974.

Mushini, S.C., P.T. Jayachandran, R.B. Langley, J.W. MacDougall, and D. Pokhotelov, Improved amplitude- and phase-scintillation indices derived from wavelet detrended high-latitude GPS data, GPS Sol., 16 (3), 363-373, 2012.

Nagorsky, P.M., Inhomogeneous structure of F-region ionosphere produced by rockets, Geomag. Aeron., 38, 100-106, (in Russian), 1998.

Ozeki, M., and K. Heki, Ionospheric holes made by ballistic missiles from North Korea detected with a Japanese dense GPS array, $J$. Geophys. Res., 115, A09314, DOI: 10.1029/2010JA015531, 2010

Perevalova, N.P., E.L. Afraimovich, S.V. Voeykov, and I.V. Zhivetiev, Parameters of large scale TEC disturbances during strong magnetic storm on October 29, 2003, J. Geophys. Res., 113, A00A13, DOI: 10.1029/2008JA013137, 2008.
Perov, A.I., and V.N. Kharisov, GLONASS: Principles of Construction and Functioning, Radiotekhnika, Moscow, 720 p. (in Russian), 2005.

Polyakova, A.S., and N.P. Perevalova, Investigation into impact of tropical cyclones on the ionosphere using GPS sounding and NCEP/NCAR Reanalysis data, Adv. Space Res., 48 (7), 11961210,2011

Qian, L., A.G. Burns, P.C. Chamberlin, and S.C. Solomon, Variability of thermosphere and ionosphere responses to solar flares, J. Geophys. Res., 116, A10309, DOI: $10.1029 / 2011 \mathrm{JA} 016777,2011$

Rolland, L.M., P. Lognonne, E. Astafyeva, E.A. Kherani, N. Kobayashi, M. Mann, and H. Munekane, The resonant response of the ionosphere imaged after the 2011 off the Pacific coast of Tohoku Earthquake, Earth Planets Space, 63, 853-857, 2011.

Rudenko, G.V., and A.M. Uralov, Calculation of ionospheric effects due to acoustic radiation from an underground nuclear explosion, J. Atmos. Terr. Phys., 57 (3), 225-236, 1995.

Schaer, S., W. Gurtner, and J. Feltens, IONEX: The Ionosphere Map EXchange Format Version 1, Proc. IGS AC Workshop. Darmstadt. Germany. February 9-11. 1998, 233-247, 1998.

Shanmugam, S., J. Jones, A. MacAulay, and A.J. Van Dierendonck, Evolution to Modernized GNSS Ionospheric Scintillation and TEC Monitoring, IEEE/ION PLANS 2012, Myrtle Beach, SC, Session B2A, 2012.

Somsikov, V.M., Solar terminator and atmosphere dynamics, AlmaAty, Publishers, Science, 192 p. (in Russian), 1983.

Tsai, H.F., and J.Y. Liu, Ionospheric total electron content response to solar eclipses, J. Geophys. Res., 104 (6), 657-668, 1999.

Thomson, N.R., C.J. Rodger, and M.A. Clilverd, Large solar flares and their ionospheric D region enhancements, J. Geophys. Res., 110, A06306, DOI: 10.1029/2005JA011008, 2005.

Voeykov, S.V., I.K. Edemskiy, and Yu.V. Yasyukevich, A statistical study of medium-scale ionospheric disturbances generated by solar terminator registered over Japan in 2008, in: Proceedings of XXX URSI General Assembly and Scientific Symposium of International Union of Radio Science, 13-20 August 2011 Istanbul, Turkey, GP1-10, 2011.

Yasyukevich, Y.V., I.V. Zhivetiev, and A.V. Lukhnev, Regional electron content in the Baikal rift zone, Journal of radio electronics, 10, 195-204, http://jre.cplire.ru/. (in Russian), 2010.

Zhang, D.H., Z. Xiao, and Q. Chang, The correlation of flare's location on solar disc and the sudden increase of total electron content, Chin. Sci. Bull., 47, 82-85, 2002.

Cite this article as: Afraimovich E, Astafyeva E, Demyanov V, Edemskiy I, Gavrilyuk N, et al.: A review of GPS/GLONASS studies of the ionospheric response to natural and anthropogenic processes and phenomena. J. Space Weather Space Clim., $2013, \mathbf{3}$, A27. 